\title{
Proof-of-Concept Assessment of a Photofission-Based Interrogation System for the Detection of Shielded Nuclear Material
}

J. L. Jones

W. Y. Yoon

Y. D. Harker

J. M. Hoggan

K. J. Haskell

L. A. VanAusdeln

November 2000

Idaho National Engineering and Environmental Laboratory Bechtel BWXT Idaho, LLC 


\title{
Proof-of-Concept Assessment of a Photofission-Based Interrogation System for the Detection of Shielded Nuclear Material
}

\author{
J. L. Jones \\ W. Y. Yoon \\ Y. D. Harker \\ J. M. Hoggan \\ K. J. Haskell \\ L. A. VanAusdeln \\ November 2000 \\ Idaho Falls, Idaho 83415 \\ Prepared for the \\ U.S. Department of Energy \\ Under DOE Idaho Operations Office \\ Contract DE-AC07-99ID13727
}

Idaho National Engineering and Environmental Laboratory 


\begin{abstract}
A photonuclear interrogation method was experimentally assessed for the detection of shielded nuclear materials. Proof-of-Concept assessment was performed at the Los Alamos National Laboratory (LANL) TA-18 facility and used the INEEL VARITRON electron accelerator. Experiments were performed to assess and characterize the delayed neutron emission responses for different nuclear materials with various shield configurations using three "nominal" electron beam energies; 8-, 10-, and 11-MeV. With the exception of highly enriched uranium (HEU), the nuclear materials assessed represent material types commonly encountered in commerce. The specific nuclear materials studied include a solid 4.8-kg HEU sphere, a 5-kg multiple-object, depleted uranium (DU) [uranium with about $0.2 \%$ enrichment with U-235] target, and two 11-kg thorium disks. The shield materials selected include polyethylene, boratedpolyethylene, and lead. Experimental results, supported with numerical predictions, have shown that the photonuclear interrogation technique is quite capable of detecting shielded nuclear material via the direct measurement of the photofission-induced delayed neutron emissions. To identify or discriminate between nuclear material types (i.e., depleted uranium, HEU, and thorium), a ratio of delayed neutron counts at two different beam energies is utilized. This latter method, referred to as the dual-beam energy ratio Figure-of-Merit, allows one to differentiate among the three nuclear material types.
\end{abstract}




\section{ACKNOWLEDGMENTS}

We wish to express our sincere thanks for the tremendous support throughout this investigation from our Los Alamos National Laboratory (LANL) colleagues: Robert (Bob) Scarlett, Charles (Chuck) Goulding, Calvin Moss, Charles Hollas and William (Bill) Myers. They made these tests possible! In addition, we want to thank Brett King of Idaho State University, for his invaluable operational support of the INEEL VARITRON electron accelerator. 


\section{CONTENTS}

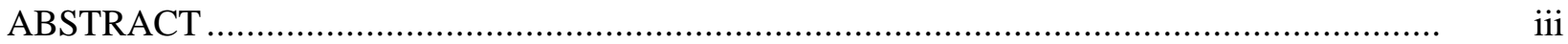

ACKNOWLEDGMENTS.......................................................................................

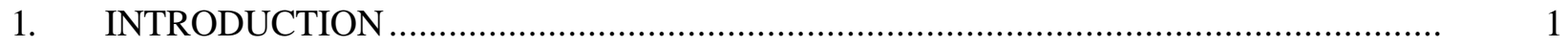

2. TECHNICAL APPROACH..................................................................................... 2

3. INTERROGATION TECHNIQUE ………………................................................. 4

4. NUMERICAL PREDICTIONS........................................................................ 5

5. EXPERIMENTAL ASSESSMENT............................................................................... 8

$5.1 \quad$ PROOF-OF-CONCEPT TESTS ..................................................................

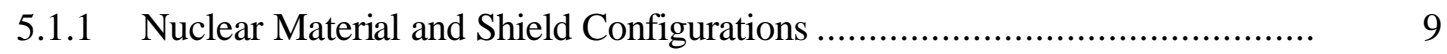

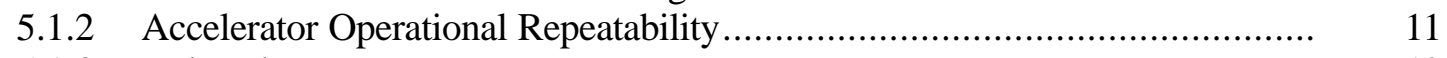

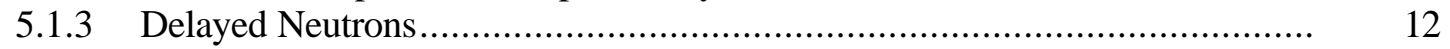

5.1.4 Dual-Beam Energy FOM Ratio ..................................................... 14

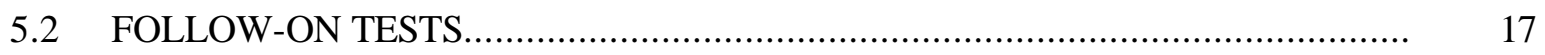

5.2.1 Electron Beam Spectra Performance Assessment.................................... 17

5.2.2 Uranium Repeatability and Thorium Results ...................................... 18

5.2.3 Additional Shielding and Cargo Container Results.................................. 19

5.2.4 Composite Uranium Material Assessment................................................ 21

6. CONCLUSIONS AND RECOMMENDATIONS .................................................. 23

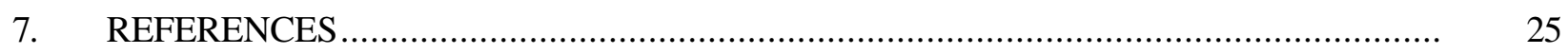

\section{FIGURES}

1. Total photonuclear yield cross sections for selected nuclear isotopes ............................ 3

2. Photofission cross sections for selected nuclear isotopes ...................................... 3

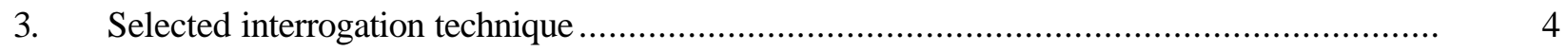

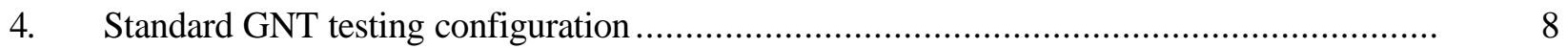

5. The "nominal" electron energy spectra selected .................................................... 9

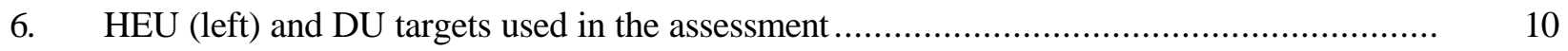

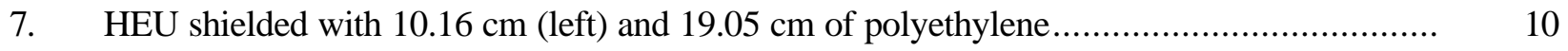

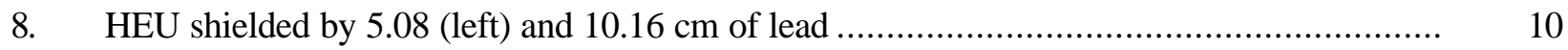


9. HEU shielded by composites of lead (5.08) and borated polyethylene $(10.16 \mathrm{~cm}) \ldots \ldots \ldots \ldots \ldots \ldots$

10. Electron beam energy spectra for a nominal 8-MeV operation......................................

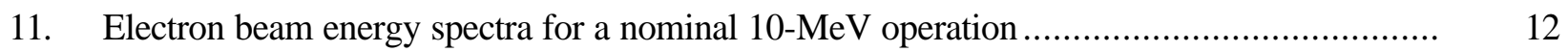

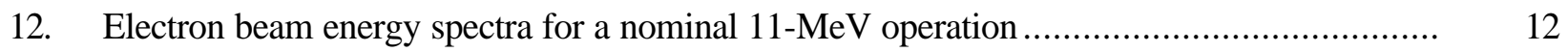

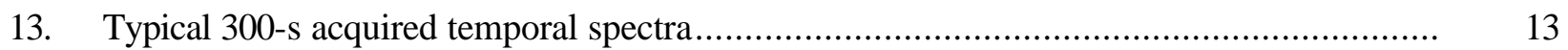

14. Delayed counts from unshielded HEU for various electron beam energies ........................ 14

15. Electron beam energy spectra for a nominal 11-MeV operation .................................... 17

16. Electron beam energy spectra for a nominal $10-\mathrm{MeV}$ operation ................................. 18

17. Electron beam energy spectra for a nominal 8-MeV operation................................. 18

18. Delayed counts per coulomb comparisons from a 4.8-kg HEU sphere............................ 19

19. Polyethylene-filled drums used to provide shielding for nuclear material located inside the center hole. [Barrel \#2 is shown with its top removed] ................................ 20

20. Drum positioned within the transport container and behind a container door ..................... 21

21. Unshielded compos ite uranium target. [Right and left views] ...................................... 22

\section{TABLES}

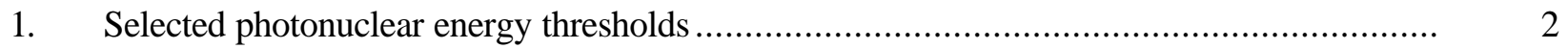

2. Unshielded Nuclear Material Delayed Responses ......................................................

3. Shielded nuclear material duatbeam energy delayed response ratios .............................. 7

4. Average neutron count rate (counts/s) in the defined "delayed" region for three

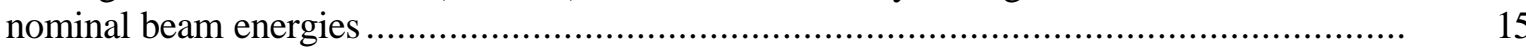

5. Dual-beam energy FOM ratios for various cases studied .......................................... 16

6. Dual-beam energy FOM ratios for bare nuclear materials in the follow-on tests................. 19

7. Dual-beam energy FOM ratios for uranium in polyethylene-filled drums ........................ 20

8. Dual-beam energy FOM ratios for uranium in polyethylene-filled drums located within a transport container.

9. Dual-beam energy FOM ratios for unshielded composite uranium 


\section{Proof-of-Concept Assessment of a Photofission- Based Interrogation System for the Detection of Shielded Nuclear Material}

\section{INTRODUCTION}

Smuggling of nuclear material, especially highly enriched uranium (HEU) [uranium having at least $80 \%$ enrichment with U-235], within normal land, sea, and air commerce is a significant national and international concern. Cargo (or transport) containers alone carry at least 70 percent of all US import/export merchandise. HEU is of paramount concern due to its serious proliferation issue and its ease of shielding due to the inherently low radiation emissions. Unfortunately, nuclear material detection is only one of many higher-priority/higher-occurrence, contraband items requiring detection by most inspection agencies. Fortunately, these agencies, such as US Customs, are becoming increasingly confident in x-ray inspection technologies and their capabilities (i.e. active interrogation techniques) to assist in the inspections.

Already commercial vendors have developed accelerator-based x-ray systems to perform transmission and backscatter imaging and, in some cases, have used neutron generators for neutron radiography. Unfortunately, these commercial systems are not adequate to address the nuclear smuggling issue; however, integrating an applicable nuclear detection system within an existing or commerciallydeveloped inspection system may be the most acceptable and cost-effective option to address the nuclear smuggling concern.

It is now widely accepted that active interrogation methods will be required to detect the presence, or confirm the absence, of shielded HEU. The Idaho National Engineering and Environmental Laboratory (INEEL), in collaboration with Los Alamos NationalLaboratory (LANL), has focused on a photonuclear stimulation of nuclear materials within a cargo container or truck using electron accelerators producing electrons having kinetic energies up to $12 \mathrm{MeV}$. Specifically, high-energy photons (i.e., bremsstrahlung) produced by an electron accelerator, stimulate photonuclear processes within an inspected object. The resulting neutrons are detected between each accelerator pulse and are used to characterize nuclear materials and identify HEU.

The basic technical approach supporting this active interrogation assessment is presented in Section 2 below2. The photonuclear stimulation was performed using a selectable-energy [2 - $12 \mathrm{MeV}]$, transportable, electron accelerator. This accele rator and the specific interrogation technique used in this assessment are described in Section 3 below3. Numerical predicted results, using mono-energetic electron beams, are presented in Section 0 below4. The experimental assessment was performed in two phases: initial tests in December of 1999 and follow-on tests in May of 2000. Section 5 below5 describes these tests and presents the associated results. The final section presents the conclusions and recommendations of this technology assessment. 


\section{TECHNICAL APPROACH}

Electron accelerators with energies below 12-MeV have found considerable industrial and medical applications and many, especially below 8-MeV, are field transportable and are used for various radiography applications. These accelerators generate bremsstrahlung (i.e., energetic photons) having energies up to the maximum electron beam energy. The maximum photon energy in a bremsstrahlung spectrum is called the end-point energy. The proposed active interrogation concept for this nuclear smuggling application leverages on these established accelerator applications and utilizes the ability to produce very penetrating photons. The system will be capable of not only detecting concealed/shielded nuclear material, but also allowing discrimination of HEU from other nuclear materials.

The high-energy portion ( $>6 \mathrm{MeV})$ of the bremsstrahlung photon spectrum from an electron accelerator will produce copious quantities of high-energy photons (i.e., $>10^{9}$ photons/s) capable of penetrating through most shielding configurations. For example, better than 25 percent of $8-$ and $12-\mathrm{MeV}$ photons will be transmitted through $2.66-\mathrm{cm}$ and $2.44-\mathrm{cm}$ of lead shielding, respectively, and more than 10 percent will penetrate through $4.42-\mathrm{cm}$ and $3.98-\mathrm{cm}$, respectively. These transmitted energetic photons may then contribute to the desired photonuclear effects in the shielded nuclear materials.

For the nuclear materials of interest in this assessment, Table 1 presents photonuclear threshold energies. These energies represent the minimum amount of photon energy required to induce a photonuclear reaction in that element. Neutrons from a photoneutron reaction, $(\gamma, n)$, are emitted promptly after the reaction occurs. Photofission reactions, $(\gamma$,fission), emit both prompt and delayed neutrons. The latter occur from the decay of the unstable, fission fragments. Due to the similarity of these threshold energies, especially for the photofission process, and based on the inherent capabilities of most commercial accelerator systems, it is extremely difficult to exploit the thresholds for material identification/discrimination. However, the delayed neutron emissions are a direct indicator of nuclear material.

Figures 1 and 2 show the total photonuclear yield and the photofission cross sections (Ref 1), respectively, for the nuclear materials of interest in this assessment. Of particular note are the photofission cross section differences in Figure 2 for each element beginning at approximately 8-MeV. The total photonuclear yield cross section includes the photofission contribution. Many of the energetic, induced photoneutrons and delayed neutrons will escape the shielded configurations and may be detected. Nuclear material identification is possible by comparing the induced-neutron emissions per beam coulomb measured at one electron beam energy to that of another electron beam energy. In this report, this method is referred to as the "dualbeam energy" ratio Figure-of-Merit (FOM).

Table 1. Selected photonuclear energy thresholds.

\begin{tabular}{lccc}
\hline Interaction Process & U-235 & U-238 & Th-232 \\
\hline$(\gamma, \mathrm{n})[\mathrm{MeV}]$ & 5.3 & 6.1 & 6.4 \\
$(\gamma$, fission $)[\mathrm{MeV}]$ & 5.8 & 5.8 & 6.0 \\
\hline
\end{tabular}




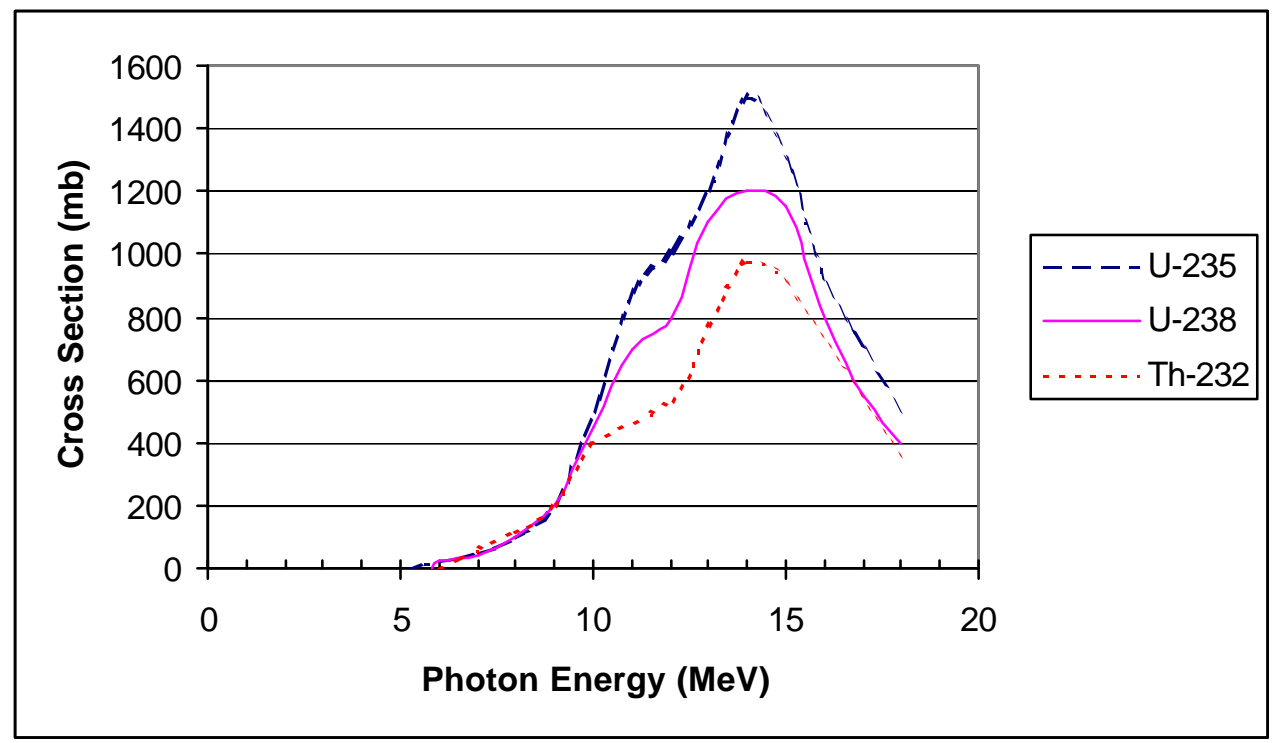

Figure 1. Total photonuclear yield cross sections for selected nuclear isotopes.

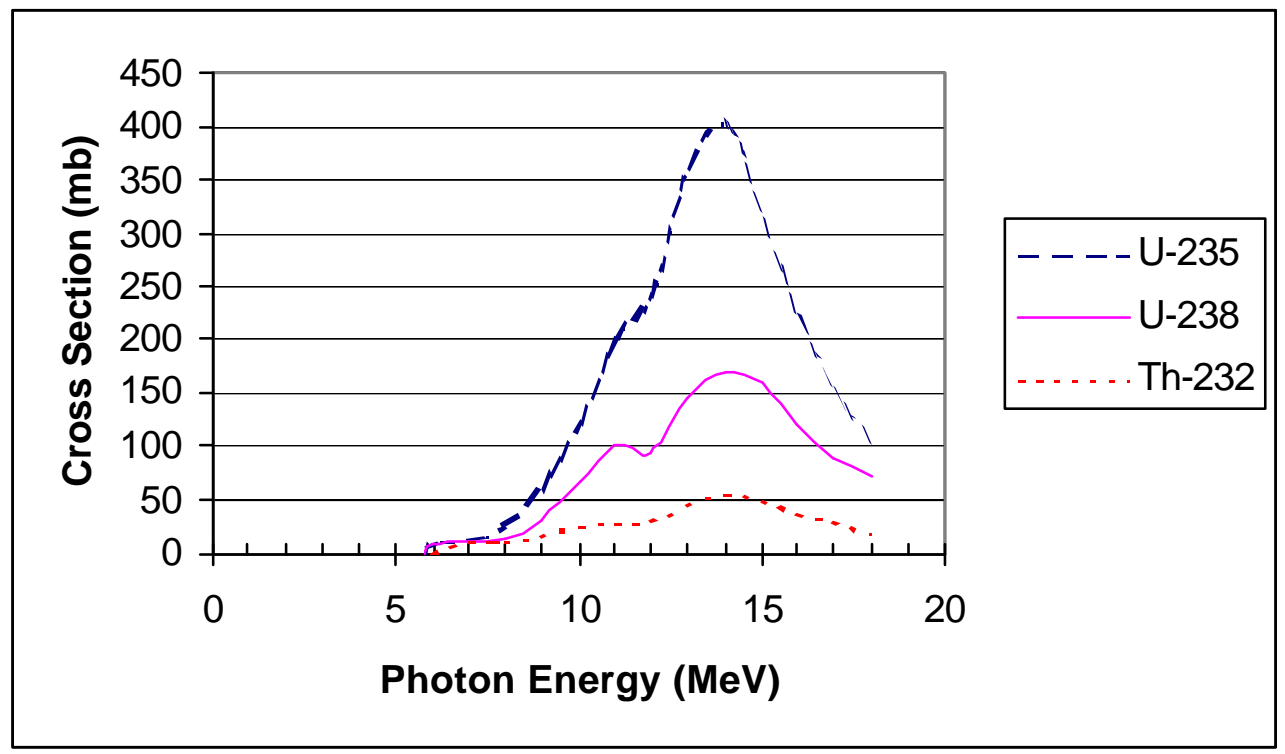

Figure 2. Photofission cross sections for selected nuclear isotopes. 


\section{INTERROGATION TECHNIQUE}

The Gamma-Neutron Threshold (GNT) active interrogation technology (Ref 2) was used as the basis of the numerical predictions and in performing the experimental assessment. The GNT technology is shown schematically in Figure 3. The system consists of a unique, transportable, selectable-energy (2 to $12-\mathrm{MeV}$ ) electron accelerator [VARITRON] and a custom-built, helium-3 based, neutron detection system. The interrogated target is typically positioned (centered) at one-meter from the x-ray source (i.e., converter) and one meter from the detector. It has been successfully demonstrated with both nuclear and non-nuclear weapon systems.

The pulsed, electron accelerator of the GNT system is a field-deployed device capable of producing bremsstrahlung photons having a continuous energy spectrum up to the maximum electron beam energy. The accelerator controls allow user-selection, control, and monitoring of various operational parameters. To allow selectable-energy operation, an on-board, magnetic spectrometer has been incorporated into the VARITRON design to provide a kinetic energy characterization of the electron beam. Different tungsten collimator shapes help define the forward-directed, electron-induced, pulsed x-rays.

The highly penetrating energetic $\mathrm{x}$-rays interact in an interrogated object (typically one-meter from the x-ray source) and induce neutrons via direct photoneutron and/or photofission interactions. The neutrons are detected with a tripod-mounted, custom-built detector connected to a portable, multichannel

\section{Gamma-Neutron Threshold (GNT) Technology}
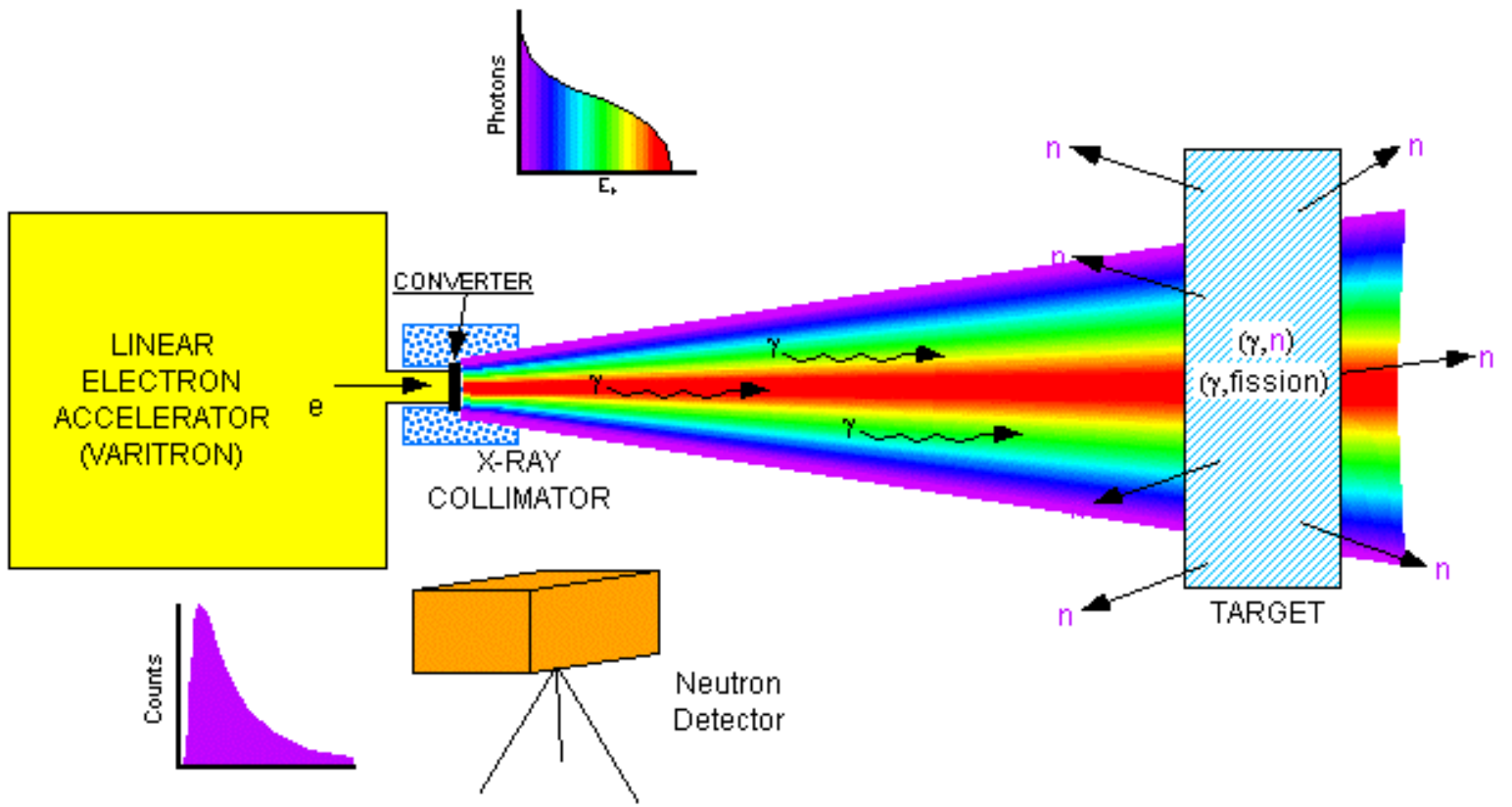

Figure 3. Selected interrogation technique. 
scalar acquisition system. The detector assembly (using four helium-3 detectors) has been specifically designed to operate in a very intense, pulsed x-ray environment. For a selected electron beam energy operation, the detected neutrons, measured between accelerator pulses, have a time-dependent response that allows the identification of delayed neutrons. These delayed neutrons, resulting from the fission process, are separable in time from the prompt neutron signature. The photofission process was the focus of this assessment. 


\section{NUMERICAL PREDICTIONS}

Initial numerical predictions using 2-11 MeV electrons were documented in August of 1999 (Ref 3) and updated in September of 2000 (Ref 4) to include extended emission response data for a 12$\mathrm{MeV}$ electron beam operation. All numerical assessments focused on monoenergetic electron beams and three nuclear material types (i.e., HEU, DU, and thorium) expected to be available at the LANL TA-18 facility. LANL provided information on an $\sim 5-\mathrm{kg}$ HEU (93-percent enriched) target consisting of four hemispherical shells. This amount of HEU material was within the critical safety requirements for these tests. The DU target consisted of four plates (enriched to 0.2-percent in U-235) with a combined weight of $4.37 \mathrm{~kg}$. The final nuclear material studied was $2.74-\mathrm{kg}$ thorium having the same dimensions as the DU. The mass difference between the DU and thorium targets was due to different physical densities.

The numerical assessment report (Ref 4) includes various nuclear material type and shielding configurations; Table 2 summarizes predictive results for the nuclear materials only (i.e., without shielding materials). In each case the nuclear material was centered at one meter from the interrogating photon source and one meter from the GNT photoneutron detector assembly. The beam energies indicated are those corresponding to mono-energetic electrons striking a bremsstrahlung-producing, tungsten target (as used in the GNT technique). Included in this table is the nuclear material type,

Table 2. Unshielded Nuclear Material Delayed Responses.

\begin{tabular}{cccc}
\hline $\begin{array}{c}\text { Material } \\
\text { Type }\end{array}$ & $\begin{array}{c}\text { Electron } \\
\text { Beam Energy } \\
(\mathrm{MeV})\end{array}$ & $\begin{array}{c}\text { Delayed Response } \\
\text { (Counts/Coul./kg) }\end{array}$ & $\begin{array}{c}\text { Delayed Response/ } \\
\text { 8-MeV Response }\end{array}$ \\
\hline HEU & 6.5 & $1.4 \mathrm{E} 4$ & 0.10 \\
& 8 & $1.4 \mathrm{E} 5$ & 1.00 \\
& 9 & $4.3 \mathrm{E} 5$ & 3.07 \\
& 10 & $1.0 \mathrm{E} 6$ & 7.14 \\
& 11 & $2.2 \mathrm{E} 6$ & 15.71 \\
\hline DU & 12 & $4.2 \mathrm{E} 6$ & 30.00 \\
& 6.5 & $2.2 \mathrm{E} 4$ & 0.07 \\
& 8 & $2.5 \mathrm{E} 5$ & 1.00 \\
& 9 & $6.8 \mathrm{E} 5$ & 2.72 \\
& 10 & $1.4 \mathrm{E} 6$ & 5.06 \\
& 11 & $3.0 \mathrm{E} 6$ & 12.00 \\
\hline & 12 & $5.6 \mathrm{E} 6$ & 22.40 \\
\hline 6.5 & $1.5 \mathrm{E} 4$ & 0.09 \\
\hline & 8 & $2.2 \mathrm{E} 5$ & 1.00 \\
& 11 & $5.1 \mathrm{E} 5$ & 2.32 \\
& 12 & $8.9 \mathrm{E} 5$ & 4.05 \\
& & $1.5 \mathrm{E} 6$ & 6.82 \\
& $2.5 \mathrm{E} 6$ & 11.36 \\
\hline
\end{tabular}


the predicted delayed counts/coulomb/kg (corresponding to neutrons detected within 1.485 to $7.665 \mathrm{~ms}$ after each accelerator pulse), and a ratio of the delayed count responses for different beam energy operations. As seen in this table for a given nuclear material type, the delayed neutron response increases with the electron beam energy. This increase in response versus electron energy is driven largely by increases in the photofission cross section (see Figure 2). A non-nuclear material will have no (or "zero") delayed neutron response. To define a figure-of-merit for comparing and/or discriminating between nuclear material types and different electron beam energies, a specific duatbeam energy figure-of-merit (FOM) ratio was developed. This FOM was selected as the ratio of the delayed neutron response for a given accelerator beam energy operation to the response using the " $8-\mathrm{MeV}$ " beam energy operation. It can be seen that the material-to-material type ratio variations increase with increasing electron beam energies. For any given beam energy, HEU consistently shows the largest ratios while thorium presents the smallest.

Table 3 presents predicted duatbeam energy delayed ratio results for HEU and DU when surrounded with low atomic number (i.e., polyethylene) and high atomic number (i.e., lead) shield configurations. It is interesting to note that these delay response ratios remain relatively unchanged for a given nuclear material for most shielding scenarios. For example, bare HEU has a $11-\mathrm{MeV} / 8-\mathrm{MeV}$ delayed response ratio of 15.71 and response ratios of 15.88 and 15.83 for the $10.16-\mathrm{cm}$ polyethylene and $5.08-\mathrm{cm}$ lead shielded configurations. The notable exceptions appear to be when the shielding begins to significantly reduce photonuclear neutron production and delayed neutron emissions. This effect can be observed for the HEU case with $10.16-\mathrm{cm}$ of lead shielding. In this latter case, only about $0.5 \%$ of any 8$\mathrm{MeV}$ photons are transmitted through the lead shield to contribute to the photofission process.

Table 3. Shielded nuclear material duatbeam energy delayed response ratios.

\begin{tabular}{|c|c|c|c|c|}
\hline $\begin{array}{l}\text { Shield Material } \\
\text { Type }\end{array}$ & $\begin{array}{l}\text { Shield } \\
\text { Thickness } \\
(\mathrm{cm})\end{array}$ & $\begin{array}{c}\text { Nuclear } \\
\text { Material } \\
\text { Type }\end{array}$ & $\begin{array}{l}\text { 10-MeV Response/ } \\
\text { 8-MeV Response }\end{array}$ & $\begin{array}{l}\text { 11-MeV Response/ } \\
\text { 8-MeV Response }\end{array}$ \\
\hline \multirow[t]{2}{*}{ None } & N/A & DU & 5.06 & 12.00 \\
\hline & & HEU & 7.14 & 15.71 \\
\hline \multirow[t]{4}{*}{ Polyethylene } & 10.16 & DU & 5.91 & 12.73 \\
\hline & & HEU & 7.06 & 15.88 \\
\hline & 20.32 & DU & 5.98 & 12.20 \\
\hline & & HEU & 7.78 & 16.67 \\
\hline \multirow[t]{4}{*}{ Lead } & 5.08 & DU & 6.31 & 12.31 \\
\hline & & HEU & 7.83 & 15.83 \\
\hline & 10.16 & DU & 6.03 & 13.42 \\
\hline & & HEU & 11.00 & 24.00 \\
\hline
\end{tabular}




\section{EXPERIMENTAL ASSESSMENT}

This experimental assessment has been divided into two phases. The first phase involved the initial proof-of-concept tests to measure the basic delayed neutron responses from selected nuclear materials surrounded by various shield materials. The second phase involved a follow-on test providing a repeatability study using an improved accelerator power supply and additional characterizations of selective shield and nuclear material types. The latter included a cargo container shield assessment.

The standard GNT interrogation configuration was used as much as possible. This standard configuration, shown in Figure 4, shows the accelerator (the box located in the upper center) positioned with its bremsstrahlung source at one meter from the center of the interrogated object (represented in this figure by the tin can located on the table). For this assessment each electron pulse was 3.5- $\mu$ s wide and was generated at a pulse rate of $125 \mathrm{~Hz}$ (i.e., $8 \mathrm{~ms}$ between each pulse). The tripod-mounted GNT neutron detector is positioned at right angle from the accelerator beam centerline and at one meter from the interrogated object. The electron accelerator uses a tungsten collimator having a maximum \pm 15 degrees divergence to control the forward extent of the bremsstrahlung output emission. The three "nominal" electron beam energy spectra used in these nuclear material detection tests are shown in Figure 5. They have been labeled as the "8-MeV," "10-MeV," and "11-MeV" spectra.

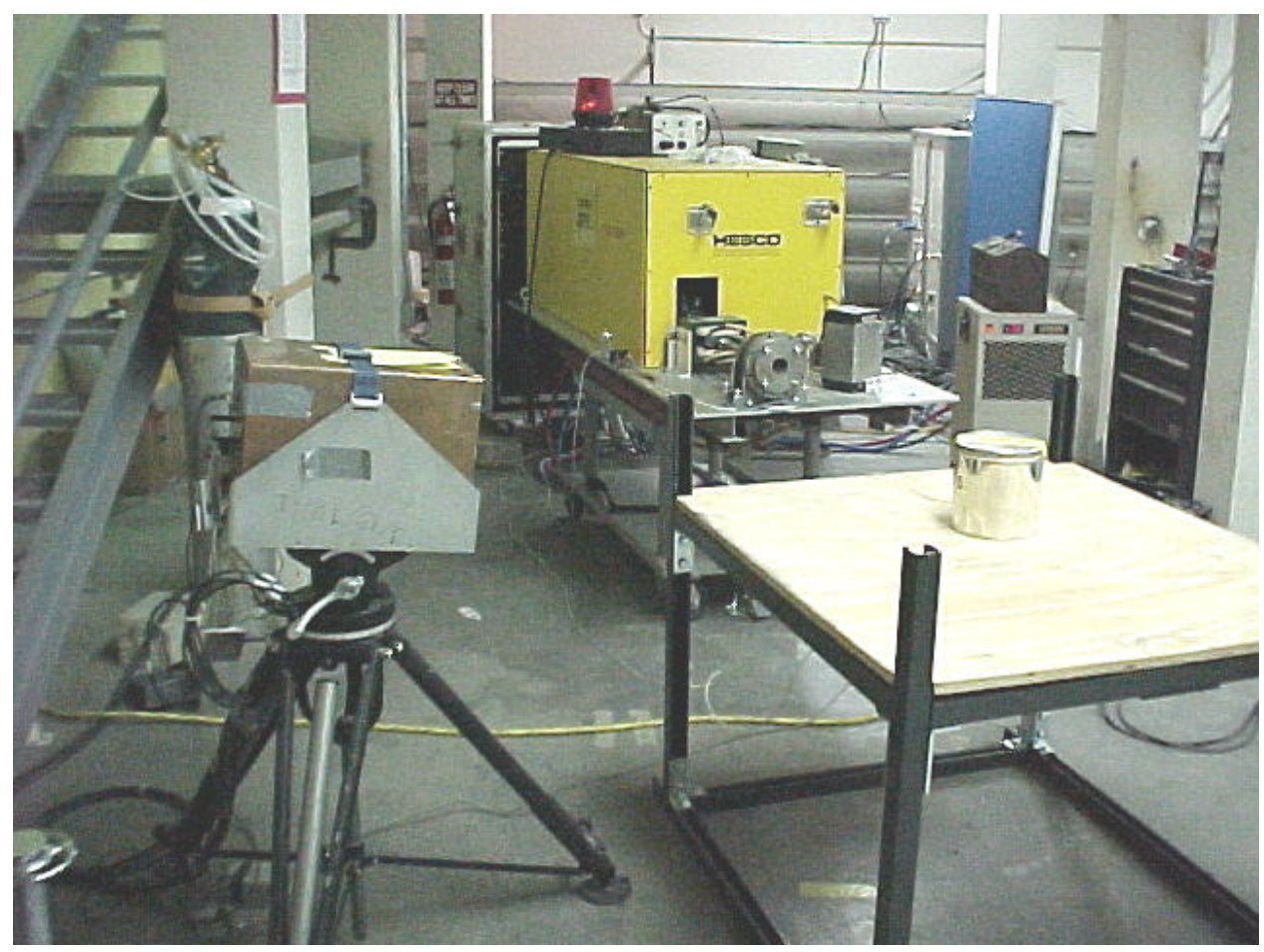

Figure 4. Standard GNT testing configuration. 


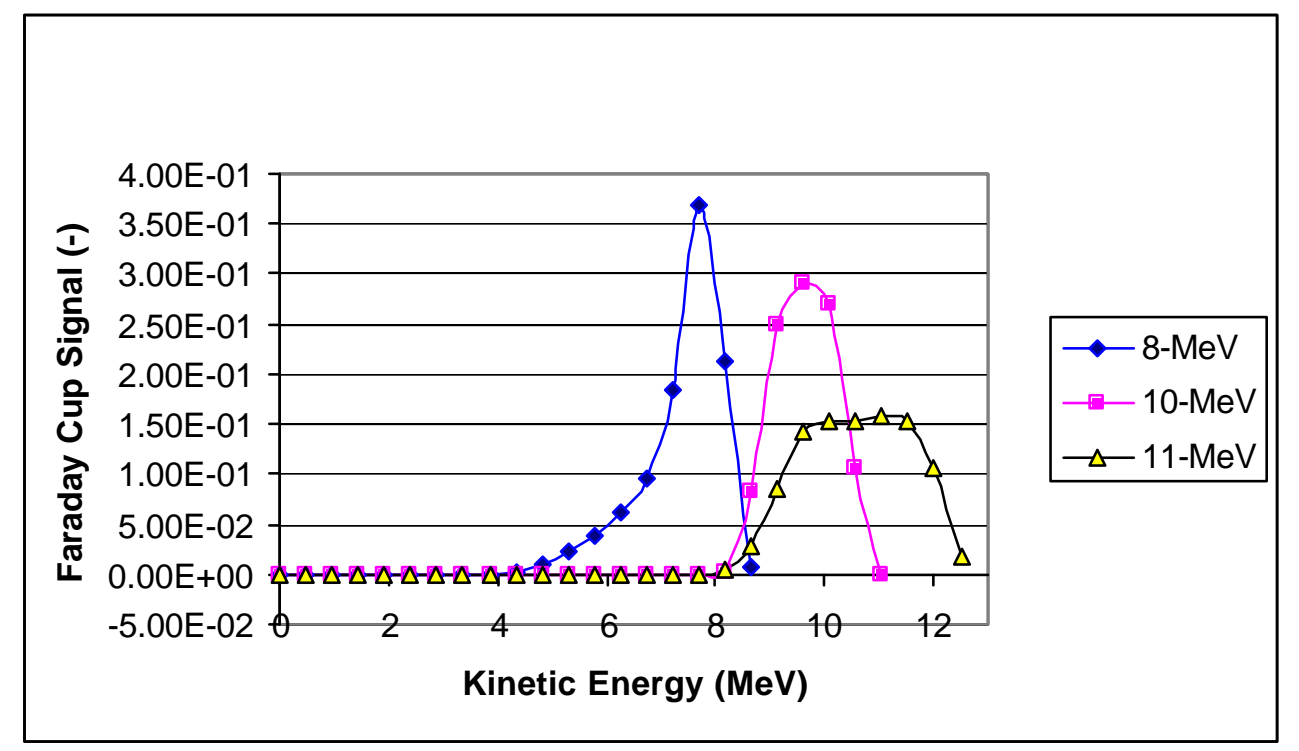

Figure 5. The "nominal" electron energy spectra selected.

In all cases the accelerator operation resulted in a photon dose to the interrogated object. This dose was initially measured by an air ionization chamber placed on the beam centerline at one-meter from the accelerator bremsstrahlung source. This average dose rate at one meter from the x-ray source was 250 , 120 , and $100 \mathrm{R} / \mathrm{min}$ for the nominal 11-, 10-, and 8-MeV operation, respectively. For general dose monitoring of each test operation, the ionization chamber was located at the accelerator table platform near the bremsstrahlung source.

\subsection{PROOF-OF-CONCEPT TESTS}

The initial proof-of-concept tests were performed at TA-18 during December 13-17, 1999. The primary objectives of this phase of the assessment were to assess the detection of delayed neutron emissions from shielded nuclear material and measure the electron beam energy dependence.

\subsubsection{Nuclear Material and Shield Configurations}

The HEU material used in these tests were not the hemispherical shells used in the numerical prediction section (see Section 4) but rather a solid 4.8-kg HEU sphere. As indicated previously, the total material amount was selected to be within the criticality safety limits for these tests. The second nuclear material was a 5-kg, multiple -object DU target consisting of a 2-kg sphere, 2-kg billet, and a 1-kg slug. Both of these nuclear material targets are shown in Figure 6. Throughout this assessment, the relative positioning of each DU object was maintained.

In addition to assessing the response of the bare nuclear materials, various shielded configurations were investigated. These configurations included 10.16 and $19.05 \mathrm{~cm}$ of polyethylene (Figure 7), 5.08 and $10.16 \mathrm{~cm}$ of lead (Figure 8), and composite shields of $5.08 \mathrm{~cm}$ of lead and $10.16 \mathrm{~cm}$ of borated polyethylene (Figure 9). 

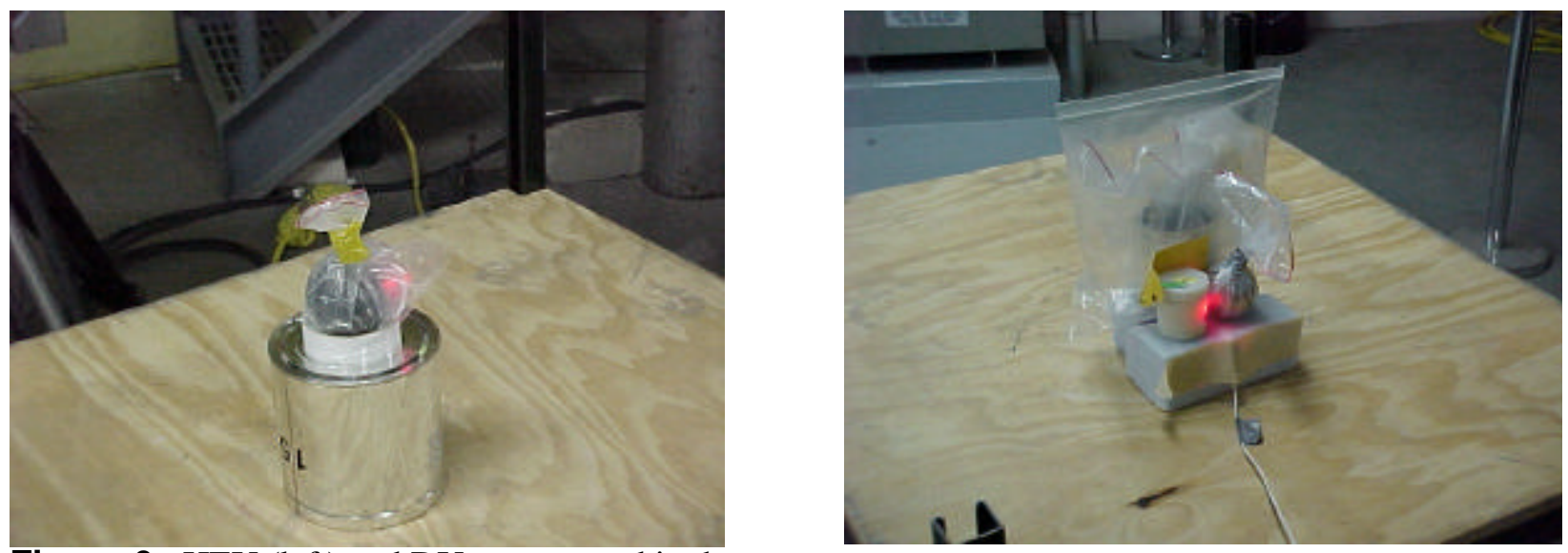

Figure 6. HEU (left) and DU targets used in the assessment.
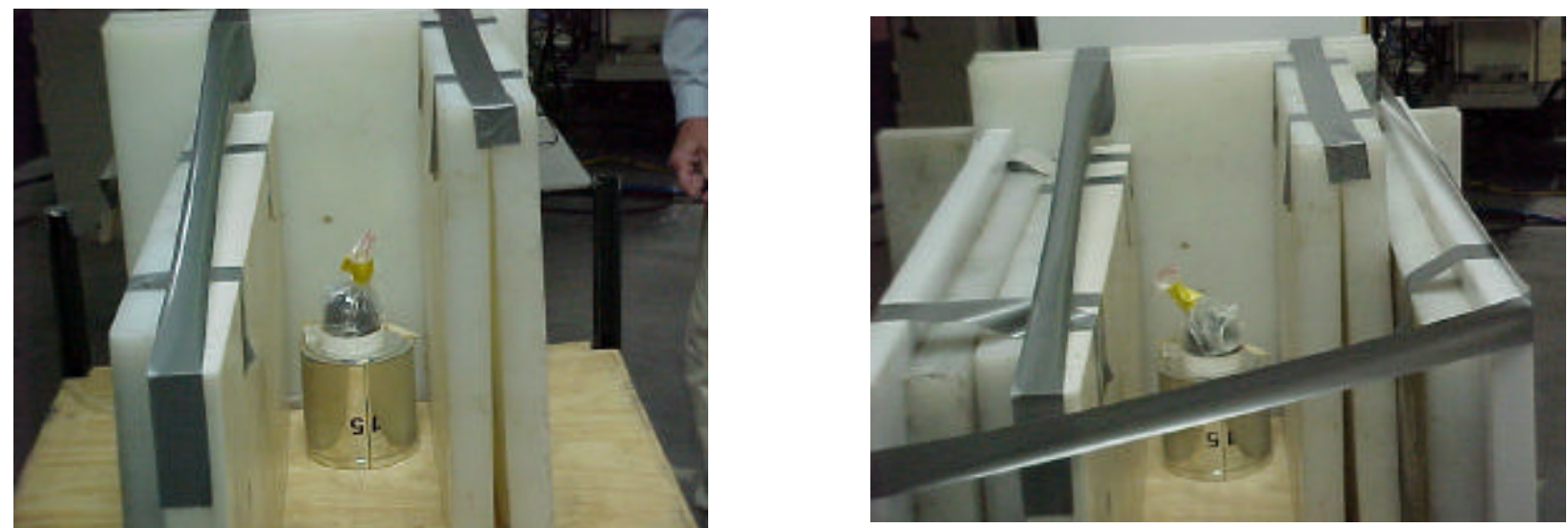

Figure 7. HEU shielded with $10.16 \mathrm{~cm}$ (left) and $19.05 \mathrm{~cm}$ of polyethylene.
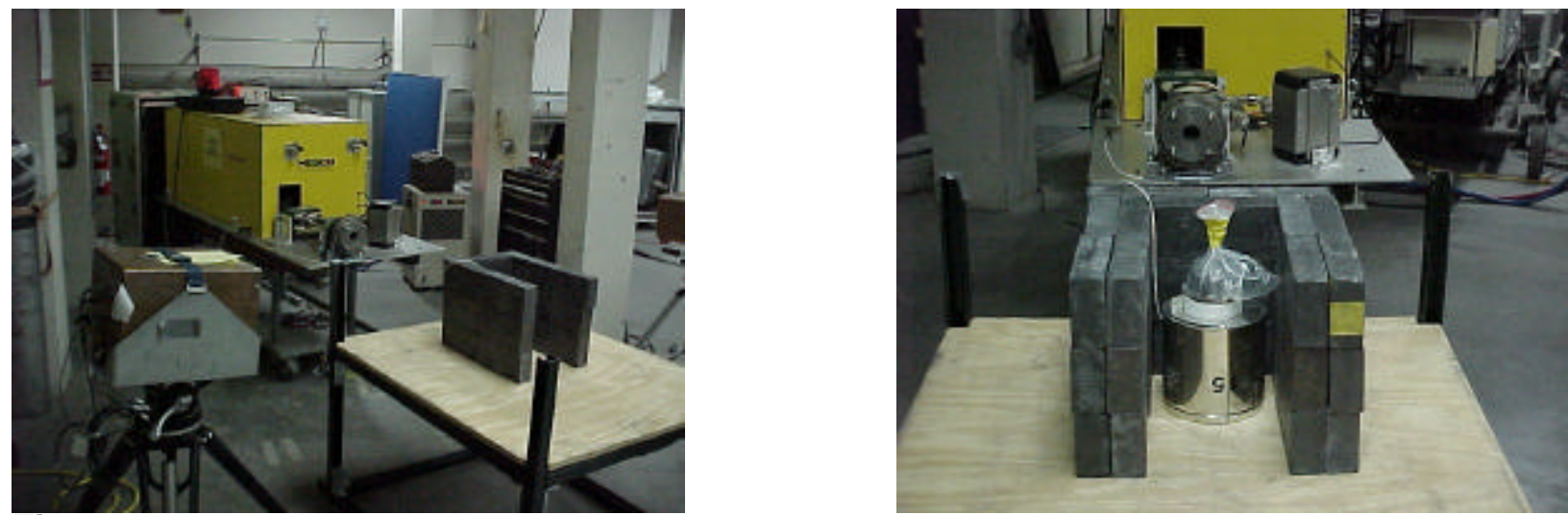

Figure 8. HEU shielded by 5.08 (left) and $10.16 \mathrm{~cm}$ of lead. 

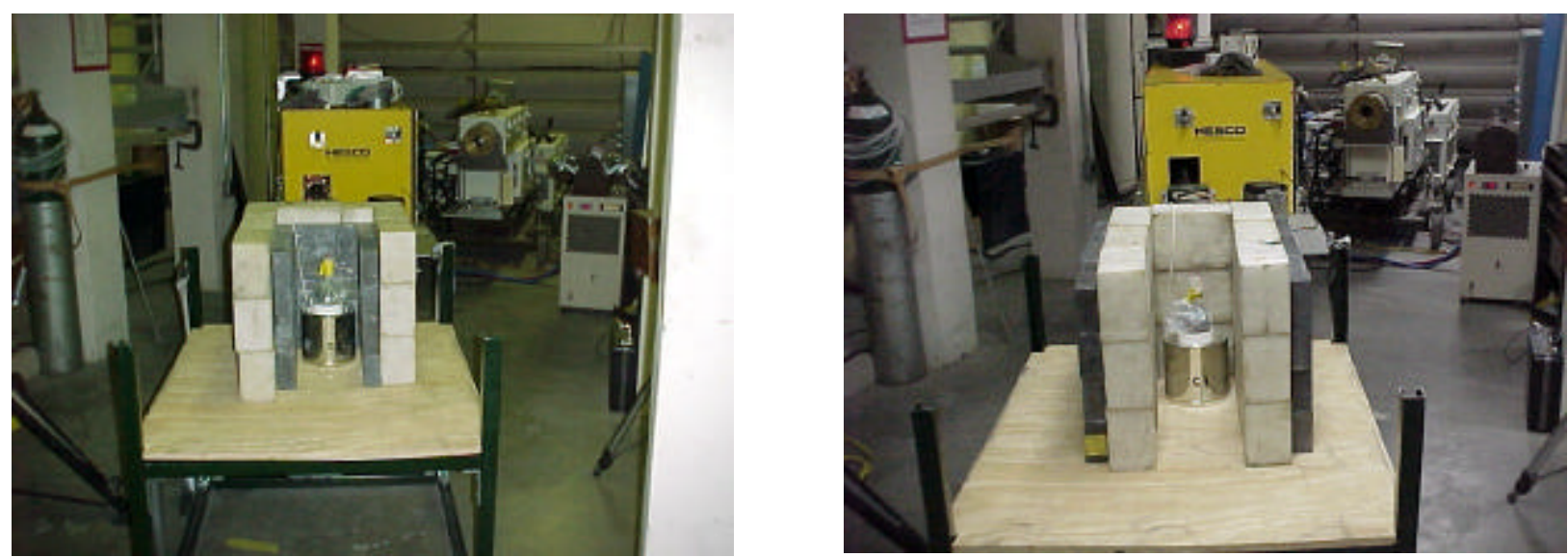

Figure 9. HEU shielded by composites of lead (5.08) and borated polyethylene $(10.16 \mathrm{~cm})$.

\subsubsection{Accelerator Operational Repeatability}

To assess repeatability in the operation of the accelerator, the electron beam spectra were acquired at various times throughout each test phase. Figures 10 through 12 show the variability of each "nominal" energy spectra throughout the initial Proof-of-Concept tests. The legends associated with each spectrum in these figures are identified with a code - MMDDX, where "MM" is the month, "DD" is the day, and " $\mathrm{X}$ " is a test specific identifier. While the spectra are not identical, especially for the "10-MeV" case, their overall characteristics do show a great degree of repeatability.

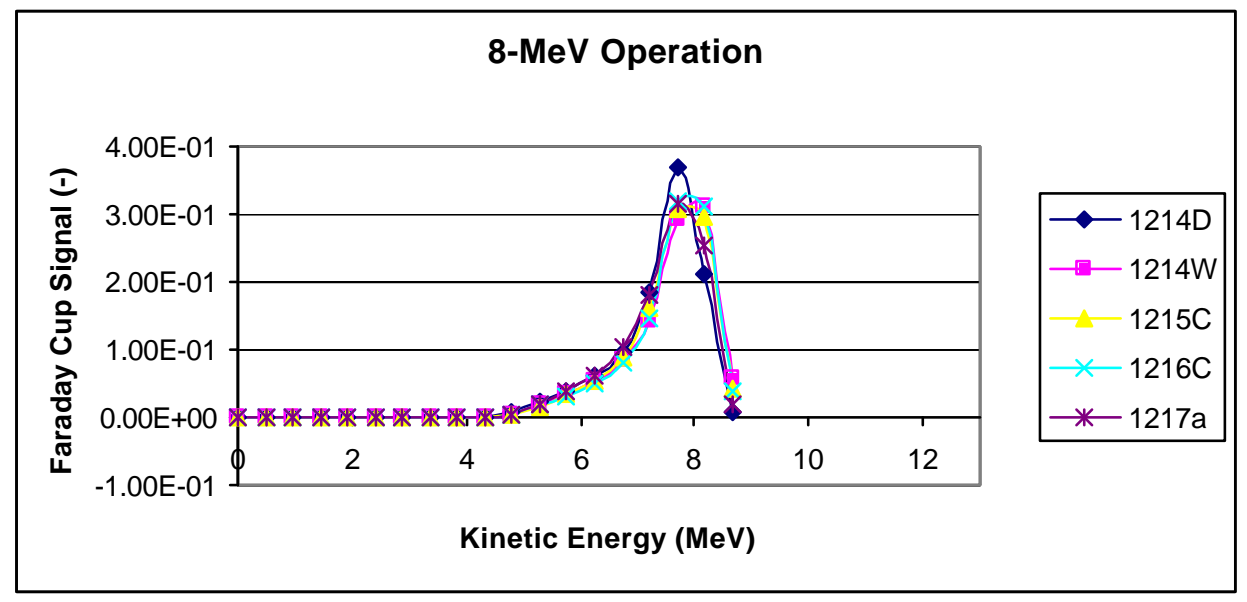

Figure 10. Electron beam energy spectra for a nominal 8-MeV operation. 


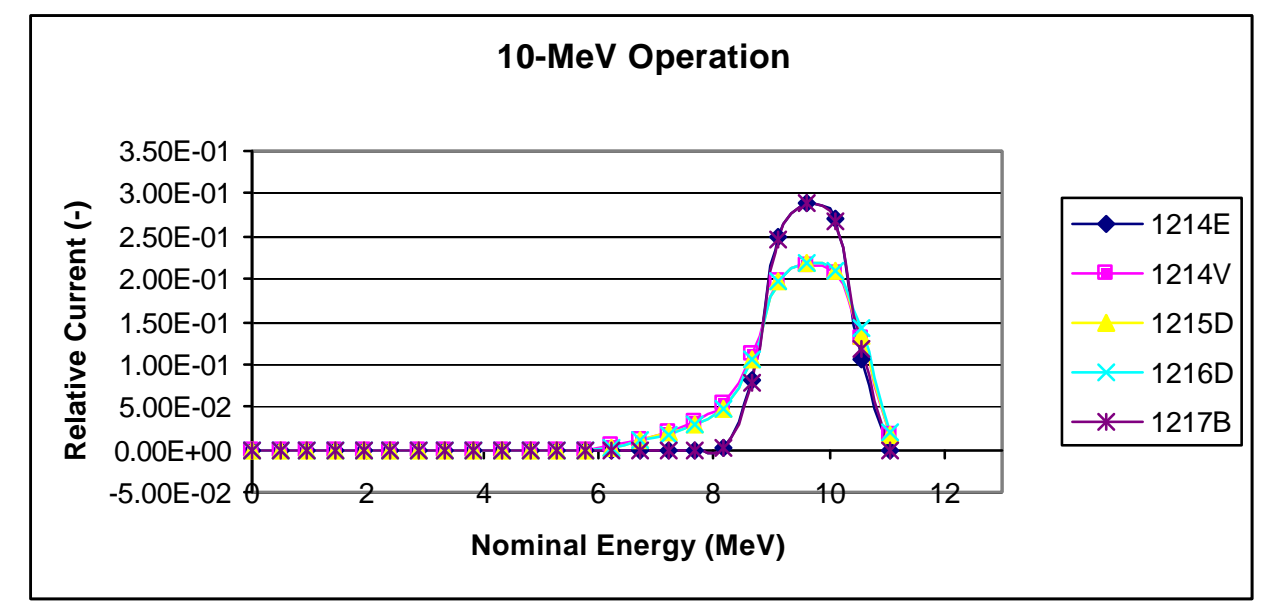

Figure 11. Electron beam energy spectra for a nominal $10-\mathrm{MeV}$ operation.

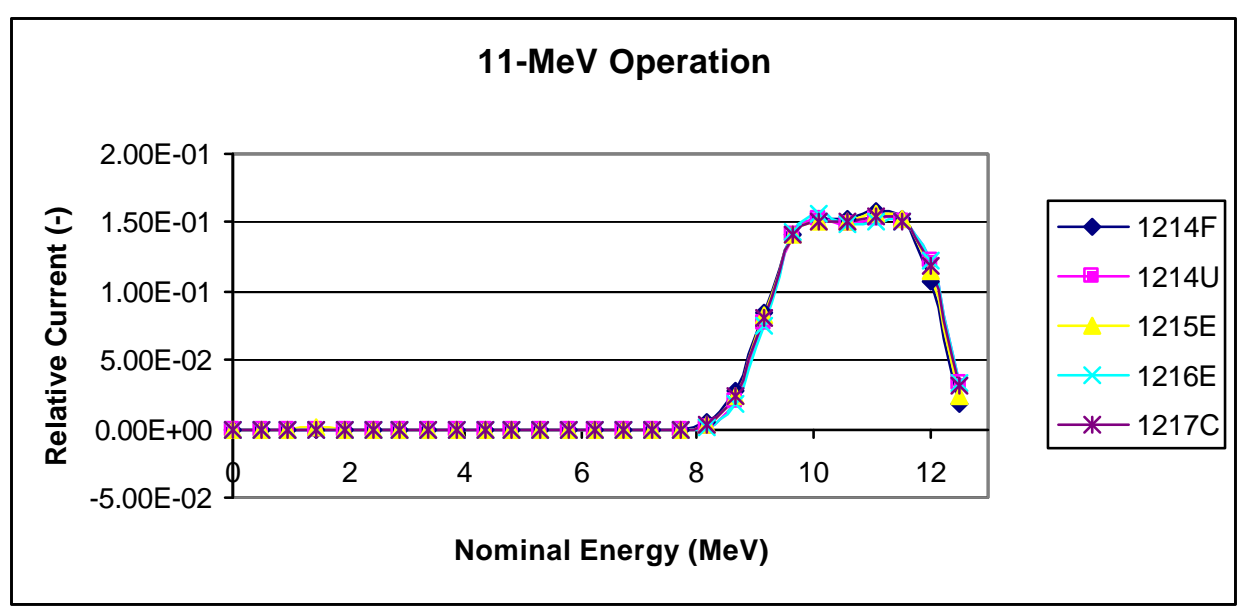

Figure 12. Electron beam energy spectra for a nominal 11-MeV operation.

\subsubsection{Delayed Neutrons}

Typical acquired temporal spectra for a representative shielded configuration with and without nuclear material are presented in Figure 13. All proof-of-concept test data were acquired in a 300-second period. In these spectra, a temporal region of 1.905 to $7.665 \mathrm{~ms}$ (corresponding to channel region 128 to 512) was selected to define the delayed neutron region after each accelerator pulse. The maximum time between each accelerator pulse is $8 \mathrm{~ms}$. The dotted horizontal lines included in this figure indicate the average counts per channel in a given detector. For this example the value is 18.182 when the nuclear material is present and 0.034 when the nuclear material is removed. These average values are immediately available to the user after an acquisition is completed.

For this interrogation method, Figure 14 shows the comparison of the numerical predictions and corresponding experimental results of the delayed counts for HEU in the non-shielded case. The predictions are based on the 5.5-kg hemispherical shell configuration discussed in section 4 and a slightly larger defined delayed region (i.e., 1.188 to $7.665 \mathrm{~ms}$ after each accelerator pulse). The excellent 

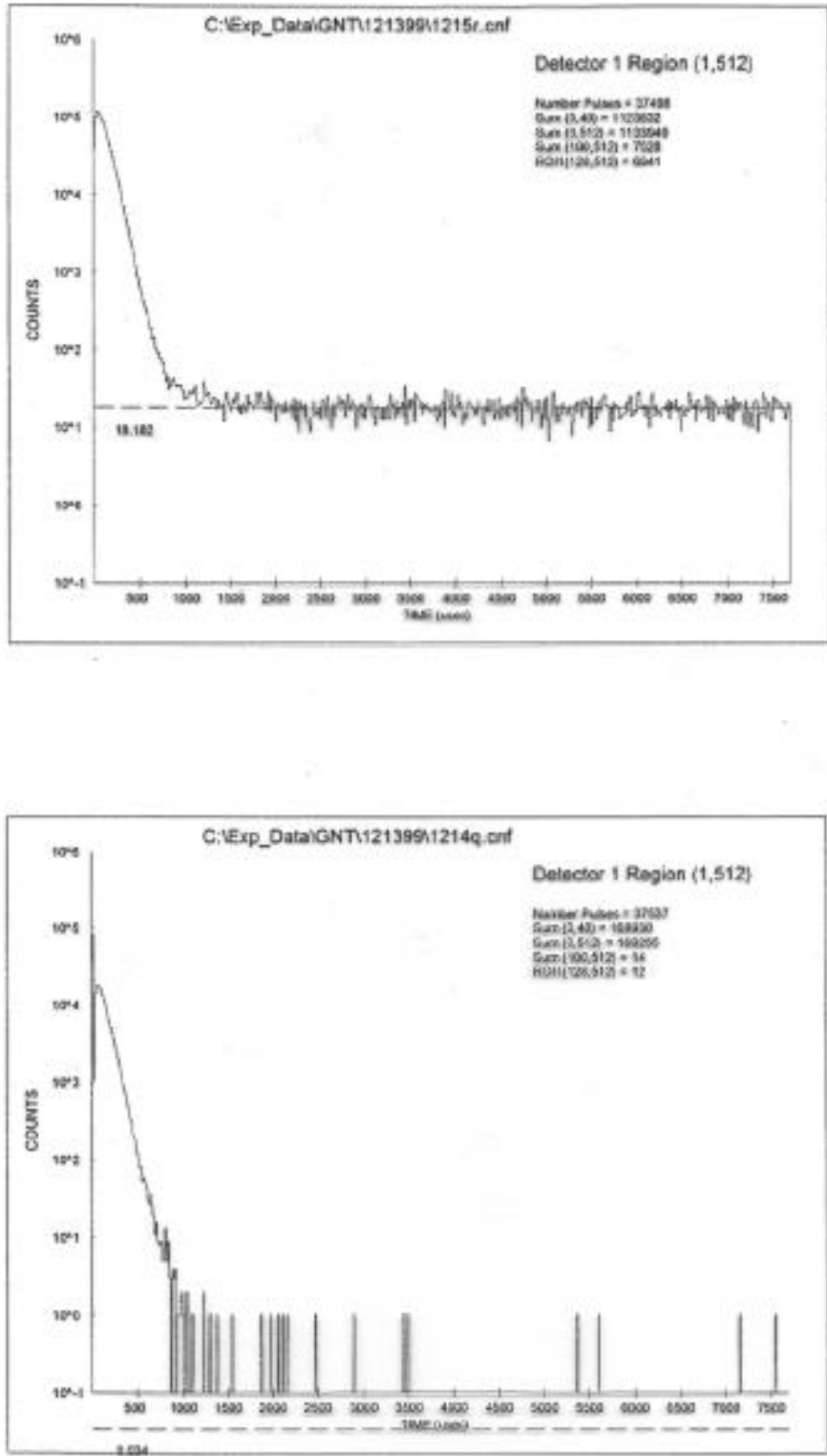

Figure 13. Typical 300-s acquired temporal spectra. 


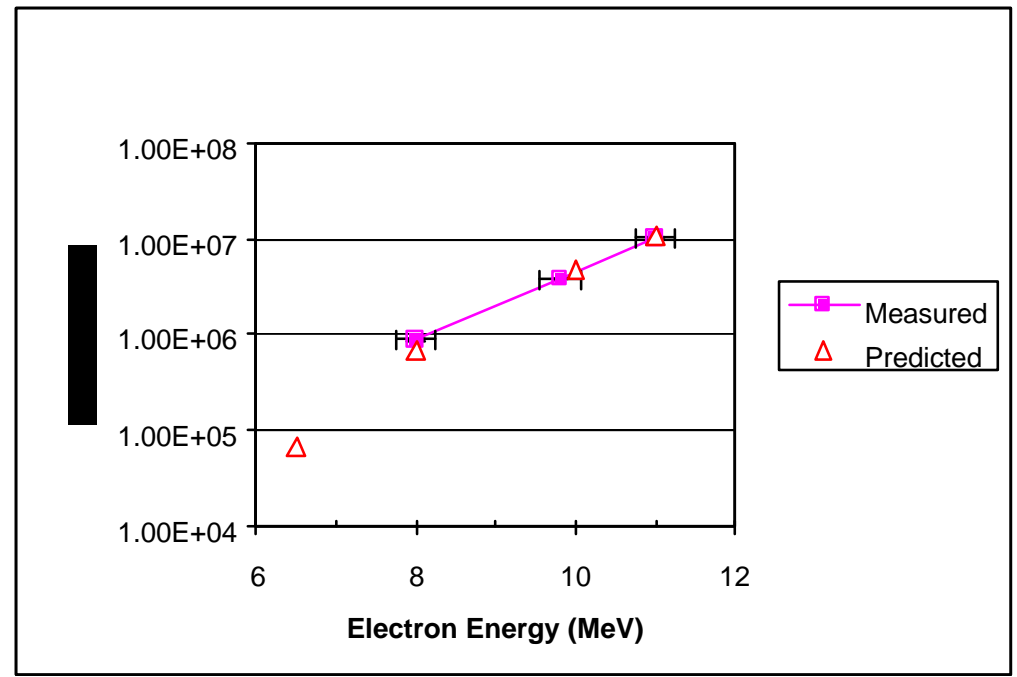

Figure 14. Delayed counts from unshielded HEU for various electron beam energies.

comparisons show the nuclear material configuration flexibility of this technique. It is estimated that the electron beam energy error is $\pm 0.25 \mathrm{MeV}$ and the delayed count data error is about \pm 2 percent.

Table 4 shows the average delayed neutron count rate (and one sigma counting error) in the GNT detector assembly (i.e., neutron counts per second) for the various nuclear materials and shield configurations studied in the December test. As indicated previously, each test was acquired for $300 \mathrm{~s}$. "Poly" indicates polyethylene and "Bpoly" represents a borated-polyethylene loaded with about 4 percent (by weight) boron. For any given energy operation, the delayed neutron response is evident at all three nominal beam energies and increases with increased beam energy. For the unshielded cases, the HEU response is almost twice the DU response at all nominal energies. For the shielded cases, the nuclear material differences are more pronounced with increasing nominal beam energies, especially for the maximum shield configurations.

The maximum delayed neutron counting rate (in the delayed region) with no nuclear material present in any shielded configuration was 0.24 counts/s for the nominal "8-MeV" operation, 0.33 counts/s for the "10-MeV" operation, and 0.36 counts/s for the "11-MeV" case. These data are presented without any "room-only" generated background corrections. Clearly a counting rate in excess of an established "background level" for a given accelerator operation will indicate the presence of nuclear material even with composite shielding.

\subsubsection{Dual-Beam Energy FOM Ratio}

In an attempt to identify and/or discriminate nuclear material that has already been indicated (via above-background, "delayed" region response) from the first nominal beam energy operation, a duat beam energy FOM ratio is obtained from the use of a second beam energy operation. Table 5 presents these FOM ratios and a one sigma error for all the bare and shielded cases studied during this test phase. Included for the reader's convenience is the prediction FOMs based on mono-energetic electrons as presented in Table 3. In all cases the experimental FOMs are less than the predicted and the resulting errors are larger than expected. However, the FOM data trend (3 to 7 for the " $10-\mathrm{MeV} / 8-\mathrm{MeV}$ " ratio and 9 to 15 for the "11-MeV/8-MeV" ratio) shows HEU with the largest value for each case studied and a relative magnitude consistency for each shield case. 
Table 4. Average neutron count rate (counts/s) in the defined "delayed" region for three nominal beam energies.

\begin{tabular}{|c|c|c|c|c|c|c|}
\hline \multirow[b]{2}{*}{ Case } & \multicolumn{6}{|c|}{ GNT } \\
\hline & 8-MeV & Error & $10-\mathrm{MeV}$ & Error & $11-\mathrm{MeV}$ & Error \\
\hline \multicolumn{7}{|l|}{ Bare } \\
\hline DU & 24.49 & 0.29 & 35.60 & 0.34 & 47.05 & 0.40 \\
\hline HEU & 36.91 & 0.35 & 64.95 & 0.47 & 96.60 & 0.57 \\
\hline 10.16 cm Poly & 0.16 & 0.02 & 0.20 & 0.03 & 0.24 & 0.03 \\
\hline DU & 1.64 & 0.07 & 2.75 & 0.10 & 3.52 & 0.11 \\
\hline HEU & 5.15 & 0.13 & 8.90 & 0.17 & 10.85 & 0.19 \\
\hline \multicolumn{7}{|l|}{$19.05 \mathrm{~cm}$ Poly } \\
\hline DU & 1.13 & 0.06 & 1.74 & 0.08 & 2.25 & 0.09 \\
\hline HEU & 1.89 & 0.08 & 3.55 & 0.11 & 5.23 & 0.13 \\
\hline \multicolumn{7}{|l|}{$5.08 \mathrm{~cm} \mathrm{~Pb}$} \\
\hline Pb Only & 0.22 & 0.03 & 0.30 & 0.03 & 0.36 & 0.03 \\
\hline $\mathrm{DU}$ & 2.19 & 0.09 & 3.77 & 0.11 & 5.01 & 0.13 \\
\hline HEU & 4.45 & 0.12 & 9.25 & 0.18 & 12.62 & 0.21 \\
\hline \multicolumn{7}{|l|}{$10.16 \mathrm{~cm} \mathrm{~Pb}$} \\
\hline Pb Only & 0.24 & 0.03 & 0.30 & 0.03 & 0.33 & 0.03 \\
\hline $\mathrm{DU}$ & 0.58 & 0.04 & 1.13 & 0.06 & 1.73 & 0.08 \\
\hline HEU & 2.07 & 0.08 & 5.02 & 0.13 & 6.02 & 0.14 \\
\hline \multicolumn{7}{|c|}{$5.08 \mathrm{~cm} \mathrm{~Pb}(\mathrm{IN}) / 10.16 \mathrm{~cm}$ Bpoly } \\
\hline $\mathrm{Pb} /$ Bpoly Only & 0.17 & 0.02 & 0.24 & 0.03 & 0.31 & 0.03 \\
\hline DU & 0.43 & 0.04 & 0.71 & 0.05 & 0.89 & 0.05 \\
\hline HEU & 1.21 & 0.06 & 2.27 & 0.09 & 3.07 & 0.10 \\
\hline \multicolumn{7}{|c|}{$10.16 \mathrm{~cm}$ Bpoly $/ 5.08 \mathrm{~cm} \mathrm{~Pb}$ (out) } \\
\hline Bpoly/Pb Only & 0.21 & 0.03 & 0.25 & 0.03 & 0.37 & 0.04 \\
\hline DU & 0.39 & 0.04 & 0.46 & 0.04 & 0.66 & 0.05 \\
\hline $\mathrm{HEU}$ & 0.65 & 0.05 & 1.25 & 0.06 & 1.58 & 0.07 \\
\hline
\end{tabular}


Table 5. Dual-beam energy FOM ratios for various cases studied.

\begin{tabular}{|c|c|c|c|c|c|c|}
\hline \multicolumn{7}{|c|}{ Energy Ratios } \\
\hline \multirow[b]{2}{*}{ GNT (avg.) Case } & \multicolumn{3}{|c|}{$10-\mathrm{MeV} / 8-\mathrm{MeV}$} & \multicolumn{3}{|c|}{ 11-MeV/8-MeV } \\
\hline & Measurement & Error & Calculation & Measurement & Error & Calculation \\
\hline \multicolumn{7}{|l|}{ Bare } \\
\hline DU & 3.71 & 0.06 & 5.60 & 8.90 & 0.13 & 12.00 \\
\hline HEU & 4.26 & 0.05 & 7.14 & 11.48 & 0.14 & 15.71 \\
\hline $10.16 \mathrm{~cm}$ Poly & 3.57 & 0.69 & - & 6.71 & 1.25 & - \\
\hline DU & 4.36 & 0.25 & 5.91 & 10.42 & 0.57 & 12.73 \\
\hline HEU & 4.22 & 0.14 & 7.06 & 10.22 & 0.32 & 15.88 \\
\hline \multicolumn{7}{|l|}{$19.05 \mathrm{~cm}$ Poly } \\
\hline \multicolumn{7}{|l|}{ Poly Only } \\
\hline DU & 3.92 & 0.27 & 5.98 & 9.62 & 0.64 & 12.20 \\
\hline HEU & 4.37 & 0.23 & 7.78 & 11.67 & 0.57 & 16.67 \\
\hline \multicolumn{7}{|l|}{$5.08 \mathrm{~cm} \mathrm{~Pb}$} \\
\hline $\mathrm{Pb}$ Only & 3.40 & 0.55 & - & 8.07 & 1.25 & - \\
\hline DU & 4.11 & 0.20 & 6.31 & 11.16 & 0.52 & 12.31 \\
\hline HEU & 5.55 & 0.19 & 7.83 & 14.17 & 0.46 & 15.83 \\
\hline \multicolumn{7}{|l|}{$10.16 \mathrm{~cm} \mathrm{~Pb}$} \\
\hline $\mathrm{Pb}$ Only & 3.30 & 0.52 & - & 6.20 & 0.96 & - \\
\hline DU & 5.08 & 0.47 & 6.03 & 14.47 & 1.27 & 13.42 \\
\hline $\mathrm{HEU}$ & 5.91 & 0.28 & 11.00 & 14.48 & 0.68 & 24.00 \\
\hline \multicolumn{7}{|c|}{$5.08 \mathrm{~cm} \mathrm{~Pb}(\mathrm{IN}) / 10.16 \mathrm{~cm}$ Bpoly } \\
\hline $\mathrm{Pb} /$ Bpoly Only & 3.50 & 0.64 & - & 8.76 & 1.51 & - \\
\hline DU & 4.31 & 0.48 & - & 9.82 & 1.06 & - \\
\hline HEU & 4.84 & 0.31 & - & 11.90 & 0.74 & - \\
\hline \multicolumn{7}{|c|}{$10.16 \mathrm{~cm}$ Bpoly $/ 5.08 \mathrm{~cm} \mathrm{~Pb}$ (out) } \\
\hline Bpoly/Pb Only & 3.15 & 0.54 & - & 8.07 & 1.27 & - \\
\hline DU & 3.17 & 0.40 & - & 7.71 & 0.90 & - \\
\hline HEU & 5.03 & 0.44 & - & 11.48 & 0.98 & - \\
\hline
\end{tabular}




\subsection{FOLLOW-ON TESTS}

Follow-on experiments were performed during May 1-5, 2000. As with the initial December tests, these tests were performed in the basement of the LANL TA-18 building. In this second test series, a modification to the accelerator's pulsed, radio-frequency power supply was made to improve run-to-run operational performance. In addition, to assure better counting statistics in all acquired data, each data acquisition was for $600 \mathrm{~s}$ instead of the earlier $300 \mathrm{~s}$ operations. The specific objectives of the follow-on tests were to: 1) assess the accelerator operational performance with the modified power supply, 2) demonstrate repeatability of the December test results, 3) assess thorium material, 4) assess additional shielding configurations and cargo container effects, and 5) assess composite nuclear material.

\subsubsection{Electron Beam Spectra Performance Assessment}

The initial December tests used an accelerator power supply containing a magnetron with a constant magnetic field. To enhance the electron beam energy selection process for a given accelerator operation, a water-cooled electromagnet (EEV, Inc, Model 4261S) was added to the tunable, S-Band, magnetron (EVV, Inc., Model 5167). The addition of the electromagnet was quite useful in increasing our ability to "tune" the magnetron for a desired operation, especially to help obtain a selected maximum beam energy. The latter is of course critical to this interrogation technique. Figures 15 to 17 show the measured electron beam profiles obtained at various times throughout these follow-on tests. Note the excellent overlap of the higher energy regions. Also seen in these figures are random, single-channel, noise spikes. Investigations are continuing into the possible source(s) of this electrical noise. As yet, no negative effects have been identified as a result of these spikes.

One undesirable side effect of the enhanced "tuning" flexibility at higher beam energies is a slight reduction of the control of the lower energy portion of a spectrum. Since the lower energy electrons contribute very little, if any, to the functionality of this interrogation technique, these minor variations are quite acceptable.

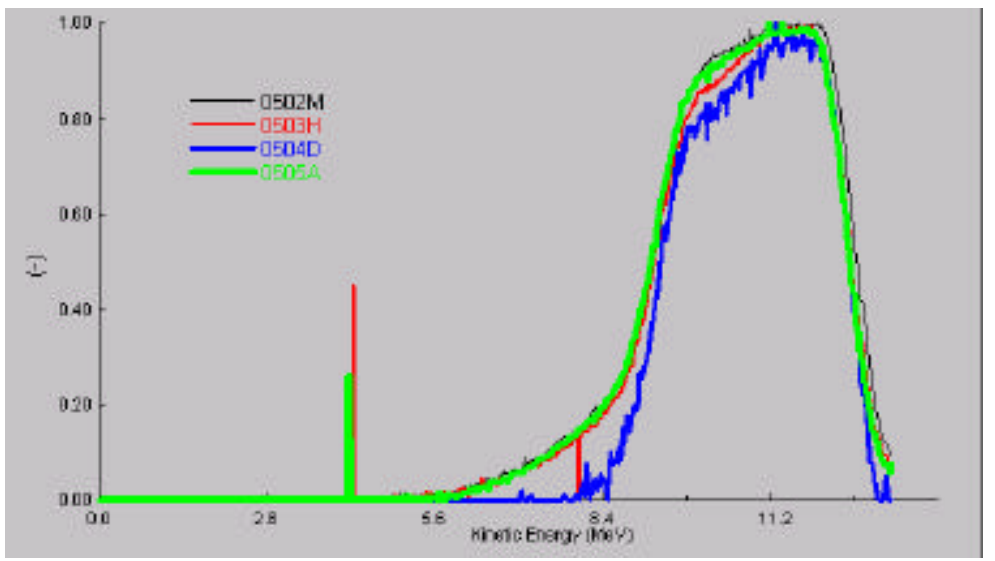

Figure 15. Electron beam energy spectra for a nominal 11-MeV operation. 


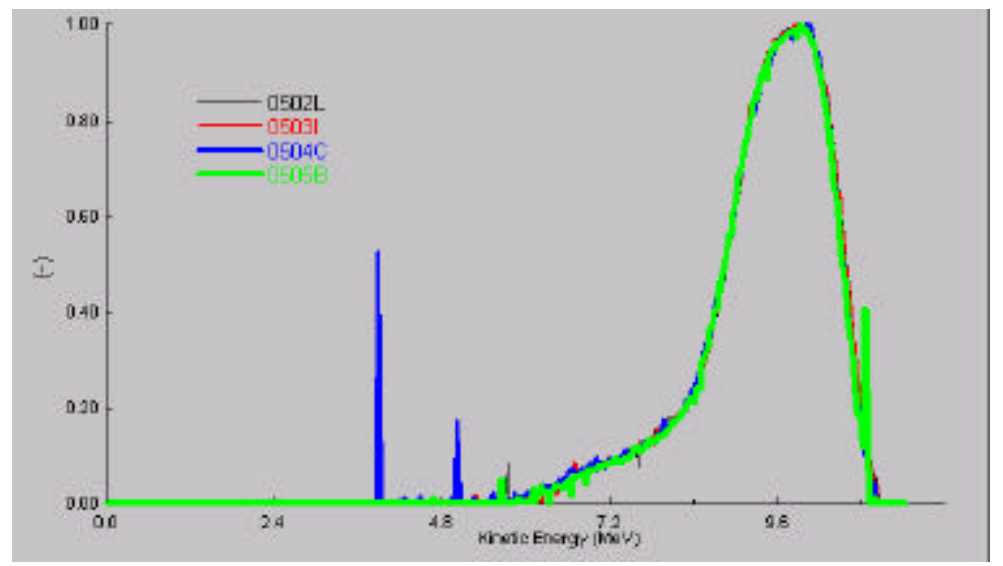

Figure 16. Electron beam energy spectra for a nominal 10-MeV operation.

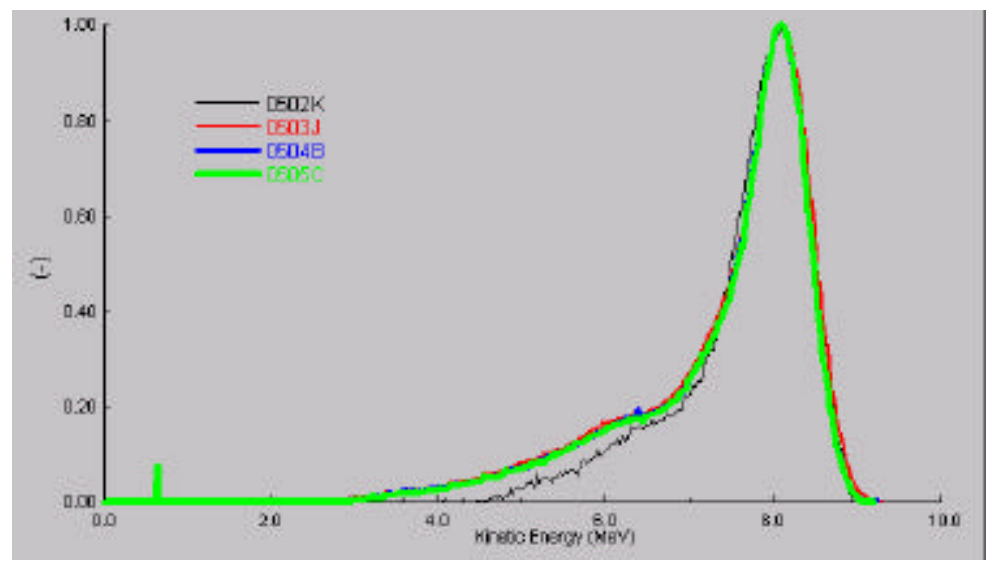

Figure 17. Electron beam energy spectra for a nominal 8-MeV operation.

\subsubsection{Uranium Repeatability and Thorium Results}

The 4.8-kg sphere of HEU used in the December tests was used to perform a repeatability assessment. As in the initial tests, the sphere was positioned at 1-meter from both the detector and the accelerator's x-ray source. Figure 18 shows the delayed count per coulomb for the three nominal beam energies. Note the excellent comparison and repeatability between data acquired almost five months apart and involving two complete experimental set-ups and tear-downs.

In addition, a 22-kg thorium target was also assessed. The thorium was configured as two, 11-kg disks having an approximate $38.1-\mathrm{cm}$ diameter. Table 6 presents the "10/8-MeV" and "11/8-MeV" delayed count FOM ratios for the thorium and uranium nuclear materials. Comparison to Table 3 (calculated) shows that the "10/8-MeV" data compares well; however, the "11/8-MeV" results have increased from the initial December tests and now compare much better to the predicted results. The higher energy FOM improvement is believed to be due to better counting statistics arising from the $600 \mathrm{~s}$ acquisition period and the improved beam energy selection capability. Thorium ratios, especially for the "11/8-MeV" case, are much less than either DU or HEU. 


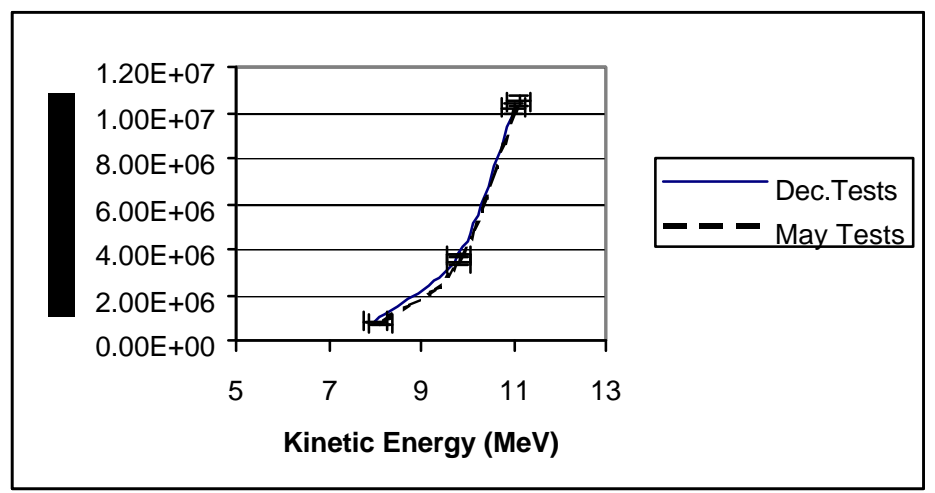

Figure 18. Delayed counts per coulomb comparisons from a 4.8-kg HEU sphere.

Table 6. Dual-beam energy FOM ratios for bare nuclear materials in the follow-on tests.

\begin{tabular}{lccccccc}
\hline & \multicolumn{3}{c}{$10-\mathrm{MeV} / 8-\mathrm{MeV}$} & & \multicolumn{3}{c}{ 11-MeV/8-MeV } \\
\cline { 2 - 3 } \cline { 6 - 7 } $\begin{array}{c}\text { GNT (avg) } \\
\text { Case }\end{array}$ & Measurement & Error & Calculation & & Measurement & Error & Calculation \\
\hline Bare & & & & & & \\
DU & 3.98 & 0.04 & 5.06 & & 11.60 & 0.12 & 12.00 \\
HEU & 4.72 & 0.04 & 7.14 & & 14.40 & 0.13 & 15.71 \\
Th & 3.05 & 0.05 & 4.05 & & 6.75 & 0.10 & 6.82 \\
\hline
\end{tabular}

\subsubsection{Additional Shielding and Cargo Container Results}

Polyethylene-filled waste drums were used to show the effects of different shield configurations. Drums provided photon/neutron shielding that effectively enclosed a nuclear material within a relatively compact configuration. One such drum, along with an interrogation set-up, is shown in Figure 19.

Two standard "55-gallon" drums were used. Centered in each drum was a 20.32-cm diameter, 1$\mathrm{cm}$ thick, polyethylene-type tube pipe into which the nuclear material was inserted. Each drum was filled with polyethylene outside the inner tube pipe. The first drum, referred to as Barrel \#1, had a net polyethylene weight of approximately $100 \mathrm{~kg}$ consisting of small "BB-sized" balls. This configuration resulted in very dense packing having an effective solid polyethylene thickness of about approximately $10 \mathrm{~cm}$. The second drum (i.e., Barrel \#2) had a net weight of $16.3 \mathrm{~kg}$ consisting of $4.45-\mathrm{cm}$ diameter, "ping-pong" balls. The effective solid polyethylene shield thickness for the latter configuration was about $1.5 \mathrm{~cm}$. Table 7 presents the electron beam energy-dependent, delay count ratios for the drum interrogations. When comparing these data to the unshielded uranium case data presented in Table 5, each nuclear material placed within each drum was detected and discriminated. 

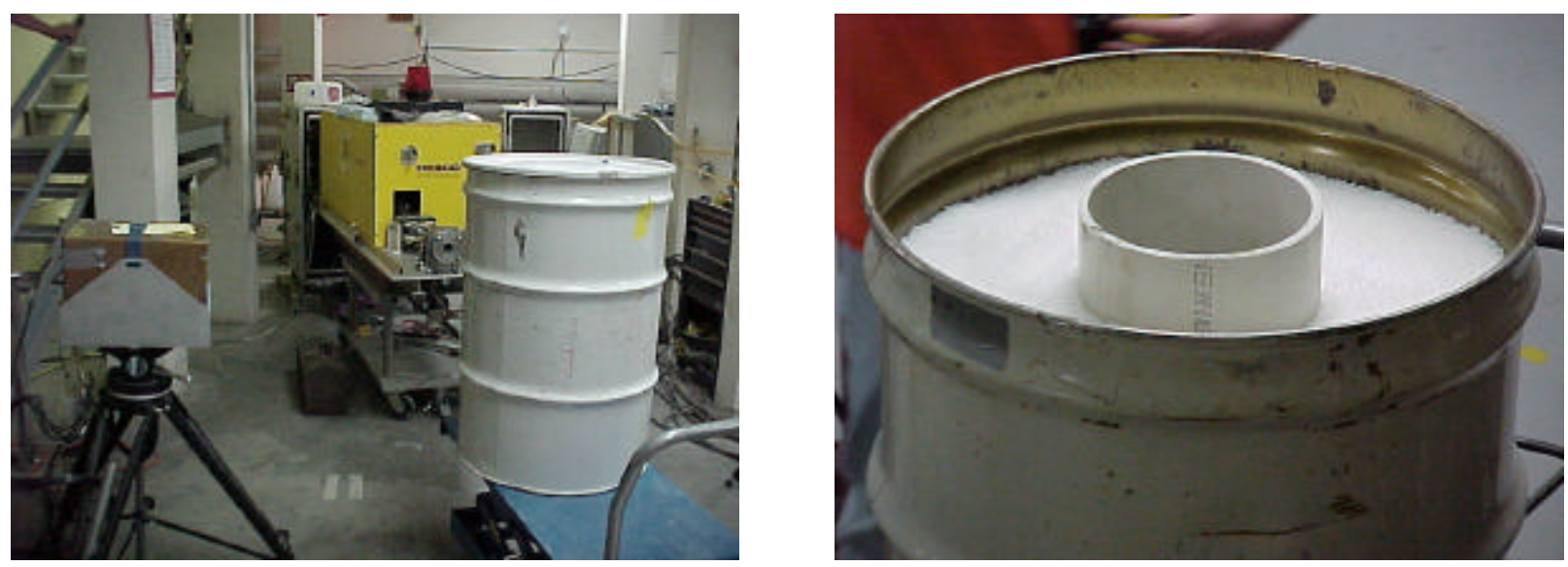

Figure 19. Polyethylene-filled drums used to provide shielding for nuclear material located inside the center hole. [Barrel \#2 is shown with its top removed.]

Table 7. Dual-beam energy FOM ratios for uranium in polyethylene-filled drums.

\begin{tabular}{|c|c|c|c|c|}
\hline \multirow{2}{*}{$\begin{array}{c}\text { GNT (avg) } \\
\text { Case }\end{array}$} & \multicolumn{2}{|c|}{$10-\mathrm{MeV} / 8-\mathrm{MeV}$} & \multicolumn{2}{|c|}{ 11-MeV/8-MeV } \\
\hline & Measurement & Error & Measurement & Error \\
\hline \multicolumn{5}{|l|}{ Barrel \#2 } \\
\hline DU & 4.05 & 0.06 & 11.20 & 0.14 \\
\hline $\mathrm{HEU}$ & 4.94 & 0.06 & 14.20 & 0.16 \\
\hline \multicolumn{5}{|l|}{ Barrel \#1 } \\
\hline DU & 4.60 & 0.29 & 11.70 & 0.70 \\
\hline HEU & 4.91 & 0.17 & 14.80 & 0.49 \\
\hline
\end{tabular}

Another shielding scenario focused on the effects of shielded nuclear material detection and discrimination when located inside a steel cargo container. To investigate this effect a half-length, standard-sized transport container was lowered into the LANL facility basement. The electron accelerator and detector were positioned at the double-door end of the container. The polyethylene-filled drum was placed inside the container. This configuration is shown in Figure 20.

The drum was positioned, behind the doors, so as to have the standard 1-meter accelerator-touranium target and uranium target-to-detector distances. Table 8 presents the duatbeam energy FOM ratios for the cargo container study. Again good discrimination of the uranium material type is noted. 

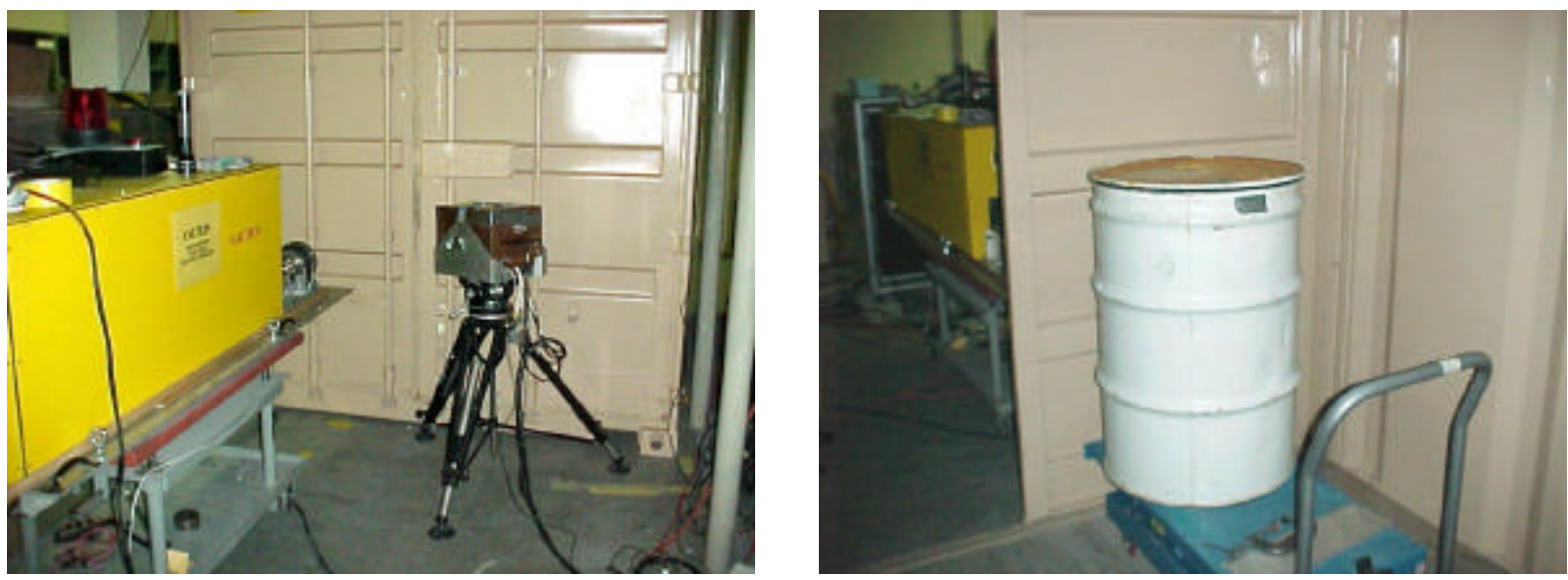

Figure 20. Drum positioned within the transport container and behind a container door.

Table 8. Dual-beam energy FOM ratios for uranium in polyethylene-filled drums located within a transport container.

\begin{tabular}{|c|c|c|c|c|}
\hline \multirow{2}{*}{$\begin{array}{c}\text { GNT (avg) } \\
\text { Case }\end{array}$} & \multicolumn{2}{|c|}{$10-\mathrm{MeV} / 8-\mathrm{MeV}$} & \multicolumn{2}{|c|}{ 11-MeV/8-MeV } \\
\hline & Measurement & Error & Measurement & Error \\
\hline \multicolumn{5}{|l|}{ Barrel \#2 } \\
\hline DU & 4.00 & 0.06 & 11.30 & 0.16 \\
\hline HEU & 4.21 & 0.05 & 13.10 & 0.15 \\
\hline \multicolumn{5}{|l|}{ Barrel \#1 } \\
\hline DU & 3.72 & 0.25 & 10.80 & 0.69 \\
\hline HEU & 4.47 & 0.18 & 14.30 & 0.54 \\
\hline
\end{tabular}

\subsubsection{Composite Uranium Material Assessment}

An assessment was performed to study unshielded, composite nuclear materials. In this case, the multi-object DU material was positioned around the HEU sphere as shown in Figure 21. The 4.8-kg sphere was positioned at one meter from the accelerator (i.e., x-ray source) and was always directly exposed to the interrogating photons. Table 9 presents the delayed neutron ratios as a function of decreasing quantities of DU. With HEU present in a given composite configuration, the delayed count ratio is always above 13 for the "11/8-MeV" case and above four for the other case. Future assessments will include nuclear and non-nuclear shielding effects. 

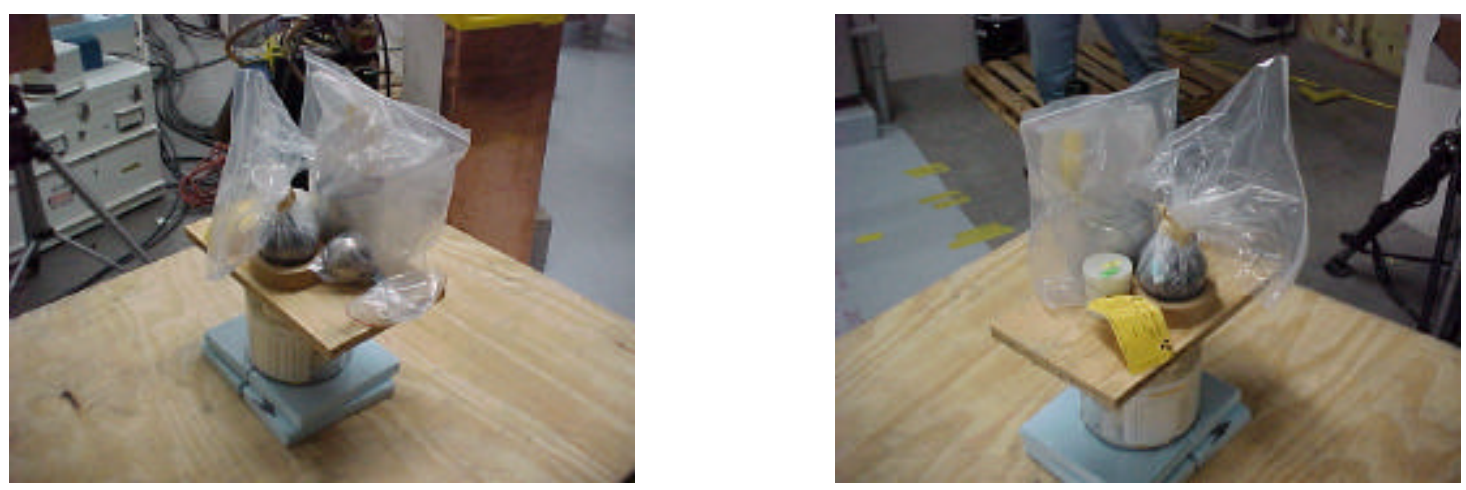

Figure 21. Unshielded composite uranium target. [Right and left views.]

Table 9. Dual-beam energy FOM ratios for unshielded composite uranium.

\begin{tabular}{lccccc}
\hline & \multicolumn{2}{c}{$10-\mathrm{MeV} / 8-\mathrm{MeV}$} & & \multicolumn{2}{c}{$11-\mathrm{MeV} / 8-\mathrm{MeV}$} \\
\cline { 2 - 3 } \cline { 5 - 6 } GNT (avg) Case & Measurement & Error & & Measurement & Error \\
\hline DU (5kg) & 3.98 & 0.04 & & 11.60 & 0.12 \\
DU (5kg) \& HEU (4.8kg) & 4.45 & 0.04 & & 14.00 & 0.10 \\
DU (3kg) \& HEU (4.8kg) & 4.92 & 0.04 & & 13.10 & 0.10 \\
HEU (4.8kg) & 4.72 & 0.04 & & 14.40 & 0.13 \\
\hline
\end{tabular}




\section{CONCLUSIONS AND RECOMMENDATIONS}

A photonuclear interrogation method was experimentally assessed for the detection of shielded nuclear materials. The technique uses energetic (up to $12 \mathrm{MeV}$ ) bremsstrahlung radiation to penetrate and induce photofission events in nuclear materials surrounded by various shield materials. The delayed neutron response from the fission events allows direct nuclear material detection and, for most shielded configurations, allows neutron multiplication for neutron-induced fissions. The latter is observed in HEU materials. Comparing the delayed neutron responses between different energy bremsstrahlung interrogations allows nuclear material identification and/or discrimination. This experimental assessment used three "nominal" electron beam energies; 8,10 , and $11 \mathrm{MeV}$. The corresponding photon dose rates at a meter corresponding to these operations are 100,120 , and $250 \mathrm{R} / \mathrm{min}$, respectively. The nuclear materials selected include a solid 4.8-kg HEU sphere, a 5-kg multiple-object, depleted uranium (DU) [uranium with about $0.2 \%$ enrichment with U-235] target, and two 11-kg thorium disks. Polyethylene, borated-polyethylene, and lead were selected as the shield materials.

All tests were performed at the Los Alamos National Laboratory TA-18 facility and used the INEEL Gamma Neutron Threshold (GNT) Technology which includes a transportable, selectable-energy, electron accelerator (i.e., VARITRON) and a neutron detection system. This experimental assessment was conducted in two phases. The initial phase was conducted in December of 1999. It concentrated on the stimulation and detection of delayed neutron responses from various shielded nuclear material configurations. A follow-on test, performed in May of 2000, built on the results of the initial tests, focused on selected shield and nuclear material response characterizations, and allowed the evaluation of a modified accelerator power supply to enhance accelerator operation (i.e., improved beam energy control). For each test phase, the accelerator system was completely set-up and operational in the facility basement within four hours of arrival using a four-man team. With the same team, the system was completely packed-up and truck-loaded in slightly over two hours.

The initial proof-of-concept tests showed that the selected HEU and depleted uranium samples could be detected (above background) through the maximum shield thickness used in these tests: 19.05$\mathrm{cm}$ polyethylene and $10.16 \mathrm{~cm}$ lead. Higher nominal electron beam operations allowed larger delayed neutron responses due to the nonlinear increase in bremsstrahlung radiation with electron beam energy. Using ratios of the delayed region response per electron beam charge (Coulombs) for different energy interrogations (also referred to as the dual-beam energy FOM ratio) showed trends which indicate selected nuclear material differentiation. Trend variations for a given material appear to be the combined result of insufficient counting statistics and accelerator operation repeatability uncertainties.

Corresponding predictions show that this material dependent ratio is relatively independent for the shield materials studied in this assessment. This is primarily due to the nearly constant penetration capability of the photons in this $8-12 \mathrm{MeV}$ energy range and the high transmission of the energetic induced neutrons.

In the follow-on tests, the modification of the accelerator's power supply using a magnetic fieldvariable, electromagnet with the magnetron unit significantly improved the accelerator's run-to-run repeatability. Specifically, the user had selective control of the energy spectrum of the accelerated electrons. This improved operation, combined with 600-second acquisitions, showed HEU results with excellent agreement to both the initial December tests and the earlier predictions. In addition, the "11$\mathrm{MeV} / 8-\mathrm{MeV}$ " FOM ratios for all the unshielded nuclear material cases, including the thorium material, resembled the original predicted ratios (e.g., $\mathrm{DU}=11.60$ [12.00 pred.], $\mathrm{HEU}=14.40$ [15.71], and $\mathrm{Th}=$ 6.75 [6.82]). Steel drums, filled with various polyethylene material densities, also showed very similar FOM ratios when the uranium material was positioned within the drum; even when a drum is positioned within a cargo container! A final study investigated the effects of an irradiation of an unshielded composite uranium configuration. In the selected configuration, the mass of multiobject, DU material was positioned behind and on either side of the HEU. The entire composite configuration was irradiated 
and centered with the accelerator beam line. With HEU present, a 3- or 5-kg DU mass maintained the FOM ratio above 13.1.

This interrogation technique appears to be able to detect kilogram quantities of nuclear material surrounded by shielding material that would easily preclude any passive detection. This detection is via the delayed neutron response resulting from the direct photofission events and subsequent neutroninduced fission events. More composite shielded and unshielded nuclear material configuration tests should be performed to study the predicted consistency in the HEU-indicating FOM ratios. These latter tests will benefit from another accelerator enhancement, currently being assessed and developed, that uses an intelligent, multi-variant analysis method to identify and correct minor variations during an accelerator operation. In addition, a larger detector can considerably decrease detection times and allow increased stand-off interrogation distances. An INEEL/LANL collaboration is addressing this recommendation for truck and cargo container detection applications. INEEL plans to develop other GNT-type detectors (smaller than LANL's detector but larger than the GNT detector used in this study) in early FY01 to complement this detection process by discriminating and locating the shielded nuclear material. 


\section{REFERENCES}

1. S. S. Dietrich and B. L. Berman, "Atlas of Photoneutron Cross Sections Obtained with Monoenegetic Photons," UCRL - 94820, June 1986.

2. J. L. Jones, et al., "Pulsed Photoneutron Interrogation: The GNT Demonstration System," WINCO-1225, INEEL Formal Report, October 1994.

3. W. Y. Yoon and J. L. Jones, "Photonuclear Response Predictions for Nuclear Smuggling Applications (U)," Classified Report, INEEL-SP-399, August 19, 1999.

4. W. Y. Yoon and J. L. Jones, "Photonuclear Response Predictions for Nuclear Smuggling Applications using 6.5 to $12 \mathrm{MeV}$ Electrons (U)," Classified Report, INEEL-SP-401, September 27, 2000. 